\title{
Kuroshio Extension Variability and Forcing of the Pacific Decadal Oscillations: Responses and Potential Feedback
}

\author{
Bo QIU \\ Department of Oceanography, University of Hawaii at Manoa, Honolulu, Hawaii
}

(Manuscript received 27 January 2003, in final form 22 May 2003)

\begin{abstract}
A forcing mechanism is sought for the large-scale circulation changes in the Kuroshio Extension region of the western North Pacific Ocean as inferred by TOPEX/Poseidon sea surface height (SSH) data. The lowfrequency signal of the Kuroshio Extension over the last decade was characterized by a modulation in its zonal mean flow intensity: the mean Kuroshio Extension jet weakened progressively from 1993 to 1996 and this trend reversed after 1997. The ability to simulate the major trends in the observed SSH signals with linear vorticity dynamics leads the authors to conclude that the modulation in the zonal mean jet was remotely forced by wind stress curl anomalies in the eastern North Pacific Ocean related to the Pacific decadal oscillations (PDOs). To be specific, the weakening (strengthening) trend in 1993-96 (1997-2001) was caused by westward expansions of negative (positive) SSH anomalies south of the Kuroshio Extension and positive (negative) SSH anomalies north of the Kuroshio Extension. Emergence of oppositely signed SSH anomalies on the two sides of the Kuroshio Extension jet is due to the different propagating speeds of the baroclinic Rossby waves, which carry the windinduced SSH anomalies generated in the eastern North Pacific at different phases of the PDOs. Hindcasting the Kuroshio Extension jet strength over the last 45 years reveals that the jet modulation has a dominant timescale of $\sim 12$ yr. Given the location of the Kuroshio Extension jet relative to the maximum atmospheric forcing, it is found that this dominant timescale is consistent with the preferred timescale under a stochastic white-noise atmospheric forcing. It is hypothesized that this connection between the Kuroshio Extension strength and the latitudinally dependent baroclinic adjustment contributes to an increase in variance and persistence of the North Pacific midlatitude coupled system on the decadal timescale.
\end{abstract}

\section{Introduction}

The Kuroshio Extension is the region of the western North Pacific occupied by the Kuroshio after it separates from the Japan coast near $35^{\circ} \mathrm{N}, 140^{\circ} \mathrm{E}$ (e.g., Mizuno and White 1983). Figure 1, adapted from Teague et al. (1990), shows the climatological surface dynamic height field, in which the axis of the eastward-flowing Kuroshio Extension is well represented by the 170 dyn cm contour. Free from the constraint of coastal boundaries, the Kuroshio Extension has long been observed to be a zonal jet accompanied by large-amplitude meanders and vigorous pinched-off eddies. While many past studies have focused on the mesoscale variability of this energetic zonal jet, several recent coupled modeling studies have highlighted the active role the Kuroshio Extension can play in generating or enhancing the decadalto-interdecadal variability of the coupled ocean-atmosphere system in the midlatitude North Pacific.

Based on coupled model simulations, Latif and Bar-

Corresponding author address: Dr. Bo Qiu, Department of Oceanography, University of Hawaii at Manoa, 1000 Pope Road, Honolulu, HI 96822.

E-mail: bo@soest.hawaii.edu nett $(1994,1996)$ show that increased advection by the Kuroshio generates warm temperature anomalies in the Kuroshio Extension and reduces the meridional sea surface temperature (SST) gradient in the central North Pacific. This reduced SST gradient works to weaken the midlatitude westerlies, resulting in a reduction in the basin-scale wind stress curl field. As the subtropical gyre spins down due to this changing wind stress field, the corresponding reduction of heat transport by the $\mathrm{Ku}$ roshio reverses the above effect, causing oscillations of the coupled ocean-atmosphere system on decadal timescales. Using a hierarchy of coupled models with different complexity of ocean dynamics, Barnett et al. (1999) indicate that while the modeled midlatitude decadal signals are driven stochastically by internal atmospheric variability (e.g., Frankignoul et al. 1997), they are enhanced by a coupled mode that has its coupling center over the Kuroshio Extension region. Inclusion of full ocean dynamics in the coupled models is shown to increase significantly the decadal variance in the midlatitude oceanic and atmospheric variables.

Adopting an improved version of the coupled model used by Latif and Barnett (1994, 1996), Schneider et al. (2002) have furthered the investigation into the mechanisms underlying the decadal signals in the mid- 


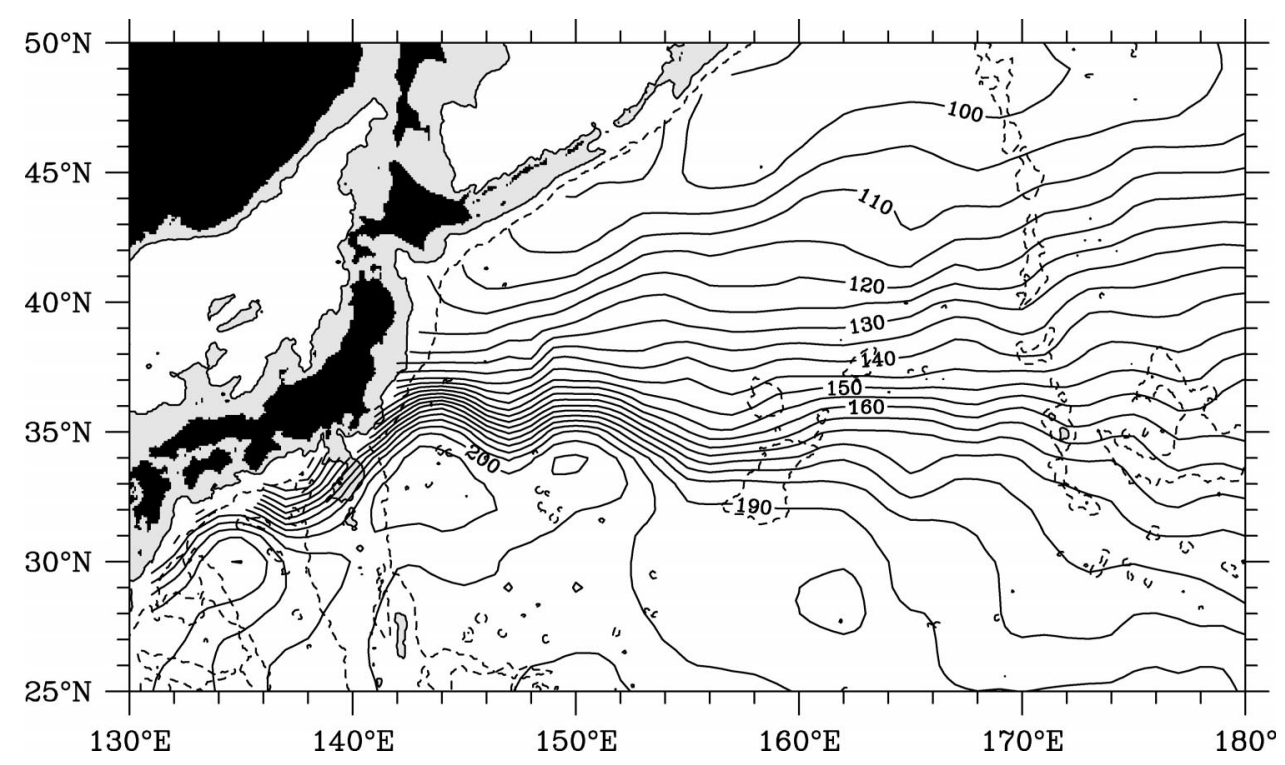

FIG. 1. Surface dynamic height field $(\mathrm{dyn} \mathrm{cm})$ relative to $1000 \mathrm{dbar}$ based on the climatology of Teague et al. (1990). Dashed lines denote the 4000-m isobaths, and areas shallower than $1000 \mathrm{~m}$ are shaded.

latitude North Pacific. In the Kuroshio-Oyashio Extension (KOE) region east of Japan, they find that it is the change in meridional position of the subtropical-subpolar gyre boundary, in response to the varying basinscale wind stress curl field, that is responsible for the wintertime SST anomalies in the region. Their examination of the surface ocean heat budget reveals that the SST anomalies in the KOE region are controlled by vertical entrainment processes. This result of Schneider et al. is in contrast to that of Latif and Barnett (1994, 1996), who found the SST anomalies in the KOE region to be generated by anomalous Kuroshio advection of the warmer tropical-origin water. The importance of meridional displacement of the subtropical-subpolar gyre boundary in creating SST anomalies in the KOE region is also emphasized by Seager et al. (2001) in their hindcast modeling study of the decadal North Pacific SST variations. Instead of vertical entrainment, Seager et al. find that the KOE SST anomalies are largely determined by the mean SST advection by anomalous horizontal currents.

By assimilating observed SST and subsurface temperature data into an upper-ocean mixed layer model, Kelly (2004) emphasized recently the importance of advective heat transport convergence associated with the Kuroshio Extension variability in determining the upper-ocean heat storage rate in the western North Pacific Ocean. On the interannual-to-decadal timescales, she found that the upper-ocean heat storage rate is better related with the advective heat transport convergence than the local surface heat fluxes.

In addition to the modeling studies, decadal modulations in the strength of the Kuroshio Extension are also examined through analyses of in situ observational data (e.g., Yasuda and Hanawa 1997; Miller et al. 1998;
Deser et al. 1999). In particular, it is found that the strengthening of the Kuroshio Extension in the 1980s lagged 4-5 yr behind the intensification of the basinscale surface wind forcing. This $4-5-y r$ lag is attributed by Miller et al. (1998) and Deser et al. (1999) to be the oceanic adjustment time required by the baroclinic Rossby waves to propagate from their excited region in the eastern North Pacific to the western boundary of the Pacific basin. From their data analysis, Deser et al. further show that the strengthening of the Kuroshio Extension is confined to the relatively narrow band of $30^{\circ}-38^{\circ} \mathrm{N}$ (see their Fig. 8). Their explanation of this confined response is that the intensified basin-scale wind forcing increases the Sverdrup flow in the subtropical and subpolar gyre interior, which in turn increases the transport of the western boundary currents and, subsequently, their downstream extensions. Because of the data constraints, Deser et al. (1999) composite the observational data in the decades before and after the North Pacific climate shift. This necessarily limits the analysis to an averaged depiction of the $\mathrm{Ku}-$ roshio Extension's response to the basin-scale wind forcing.

Measurements of the global sea surface height (SSH) field by the Ocean Topography Experiment (TOPEX)/ Poseidon (T/P) altimeter satellite over the past decade provide us now with a unique opportunity to investigate the detailed evolution of the Kuroshio Extension on the interannual-to-decadal timescales. Fortuitously, the last decade is also marked by clear phase changes in the Pacific decadal oscillation (PDO: Mantua et al. 1997; Zhang et al. 1997). For example, Fig. 2a shows the first EOF mode of the surface wind stress curl field over the North Pacific Ocean in the last two decades. As noted by many previous investigators (e.g., Trenberth and 
(a) NCEP wind stress curl EOF mode 1
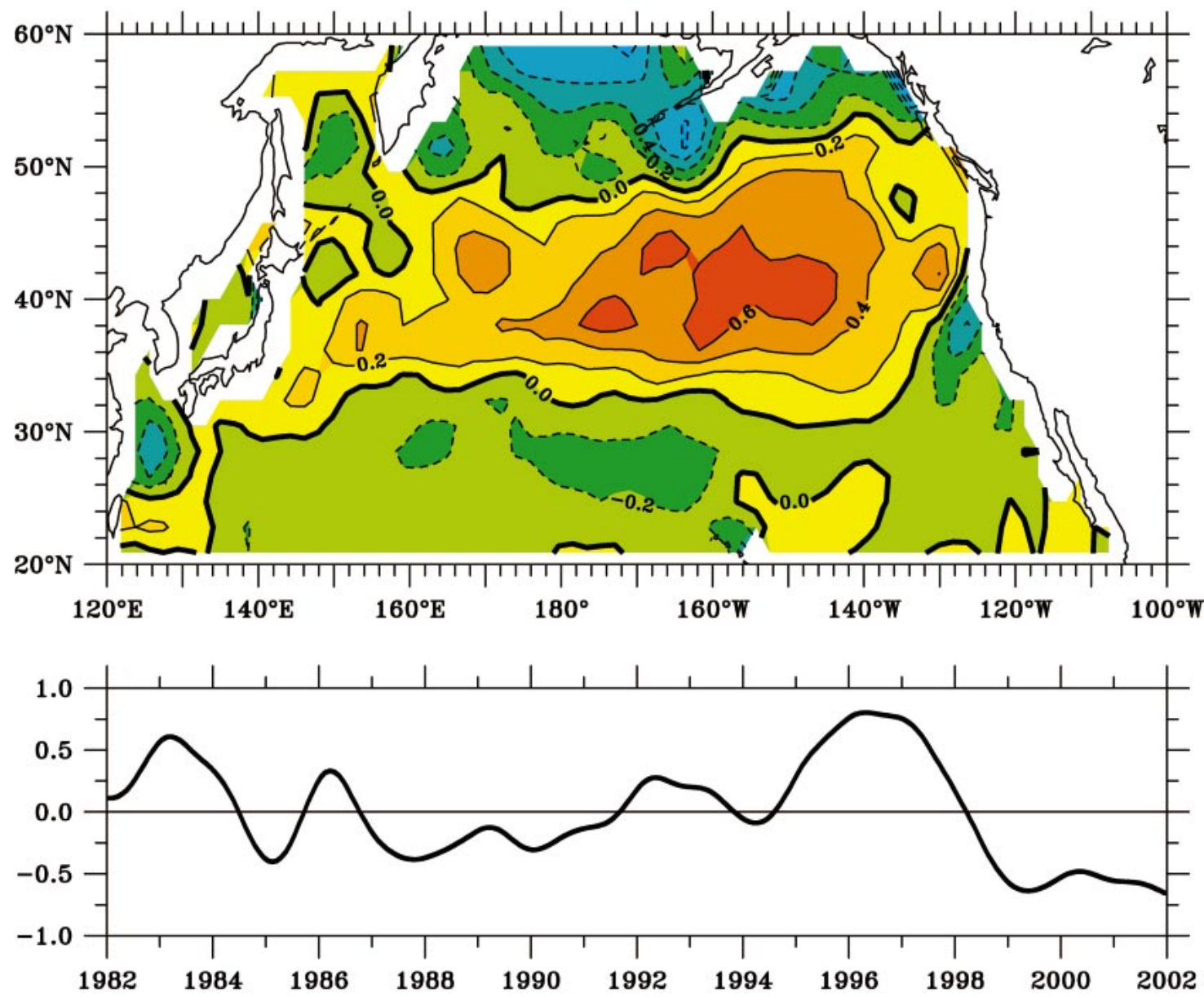

(b) Pacific decadal oscillation index

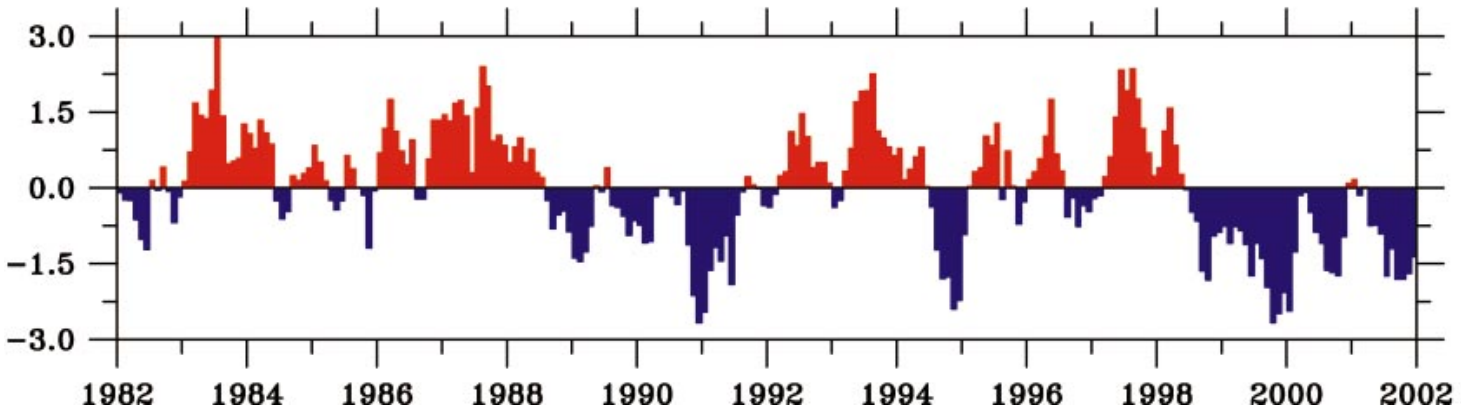

FIG. 2. (a) First EOF mode of the NCEP wind stress curl anomalies $\left(10^{-8} \mathrm{~N} \mathrm{~m}^{-1}\right)$ during $1982-2001$ over the North Pacific Ocean: the spatial pattern and its weighting function. This mode explains $17.8 \%$ of the total variance. (b) Time series of the PDO index anomalies during 1982-2001. Based on Mantua et al. (1997).

Hurrel 1994; Miller et al. 1994; Deser and Blackmon 1995; Nakamura et al. 1997; Tourre et al. 1999), the center of action of this mode is located near $40^{\circ} \mathrm{N}$ over the eastern North Pacific and its temporal variability is dominated by decadal modulations of the Aleutian low pressure system. The weighting function of this EOF mode reveals a shift from predominantly negative wind stress curl anomalies to positive anomalies in late 1992 and a sharp transition from positive to negative anomalies in early 1998 . Both of these transitions correspond well to the reversals in the PDO index (see Fig. 2b).

The objective of this study is to understand how the 


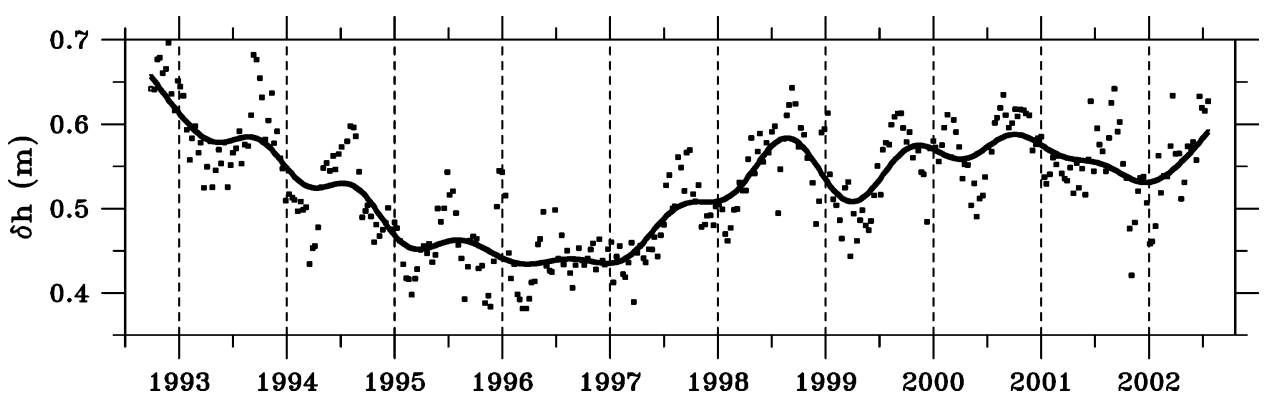

FIG. 3. Time series of zonally averaged SSH difference, $\langle\delta h\rangle$, across the Kuroshio Extension jet. For each $\mathrm{T} / \mathrm{P}$ cycle, SSH differences are first evaluated along the ground tracks and are then averaged between $142^{\circ} \mathrm{E}$ and $180^{\circ}$. Solid marks indicate the $\langle\delta h\rangle$ values from individual cycles and its low-pass filtered time series is given by the solid line.

Kuroshio Extension jet responds to the basin-scale surface wind forcing both through the T/P measurements and within a simple dynamic framework. We will show that the observed decadal modulation in the zonal mean Kuroshio Extension jet is attributable to the emergence of oppositely signed SSH anomalies across the Kuroshio Extension jet that are forced in the eastern North Pacific by the PDO-dominated surface wind fluctuations. The difference in the baroclinic Rossby wave speed between the southern and northern limits of the Kuroshio Extension jet is found to play a key role in generating the oppositely signed SSH anomalies. Because of the position of the Kuroshio Extension jet relative to the maximum atmospheric forcing, we will further show that the modulated Kuroshio Extension jet contributes to set the timescale of the North Pacific midlatitude coupled system.

This paper is organized as follows. Following a brief description of T/P SSH data processing in the next section, we describe in section 3 the decadal modulation detected in the zonal mean Kuroshio Extension jet and its kinetic energy field. The dynamics underlying this observed modulation is examined in section 4 by considering wind-forced baroclinic adjustment processes. In section 5, we explore the potential roles of the modulated Kuroshio Extension jet in setting the preferred time scale of the North Pacific midlatitude coupled system. Results of the study are summarized in section 6 .

\section{T/P altimeter data}

TOPEX/Poseidon altimeter data from the period of October 1992-July 2002 (repeat cycles 2-362) are used in this study. For all of the ground tracks crossing the North Pacific Ocean, the raw altimeter data are first adjusted for various environmental corrections, including the dry troposphere, the tides, and the inverse barometer effect. After these corrections, the height data are interpolated to a common latitude grid with an alongtrack resolution of $5.6 \mathrm{~km}$. The along-track anomalous SSH profiles are then calculated by subtracting from each height profile the temporally averaged profile (namely, the geoid plus the 9.8-yr mean SSH).
With the cold and dry air from the Eurasian continent overriding the warm waters carried by the western boundary current, the Kuroshio Extension region is where the largest air-sea surface heat exchanges take place in the Pacific Ocean (Talley 1984; Qiu and Kelly 1993). As a result, a significant part of the altimetrically measured SSH anomaly signals in this region is due to the seasonally varying surface heat flux forcing that causes expansion or contraction of the water column (e.g., Gill and Niiler 1973; Stammer 1997; Vivier et al. 1999). Because these steric height changes are not of interest to this study, they are removed from the alongtrack T/P SSH anomaly signals by using the daily net surface heat flux data from the National Centers for Environmental Prediction (NCEP) reanalysis (Kalnay et al. 1996). For the detailed procedure of this removal, readers are referred to Qiu (2002, his section 2). Once the SSH anomaly field is obtained for individual cycles (each cycle is separated by 10 days), the absolute SSH field is taken to be the sum of the mean climatological SSH field (cf. Fig. 1) and the anomaly field.

\section{Low-frequency variability of the Kuroshio Extension}

To describe the large-scale changes in the Kuroshio Extension system, we first evaluate the strength of the eastward-flowing jet of the Kuroshio Extension. Figure 3 shows the time series of the SSH difference, $\langle\delta h\rangle$, across the Kuroshio Extension jet averaged from $142^{\circ} \mathrm{E}$ to $180^{\circ}$. Here, $\delta h$ is calculated along individual $\mathrm{T} / \mathrm{P}$ tracks by first identifying the center of the Kuroshio Extension jet (where the eastward surface current is maximum), averaging the $\mathrm{SSH}$ values over the $1.5^{\circ}$ bins centered $1^{\circ}$ north and south of the jet's center $\left(h_{N}\right.$ and $h_{S}$ ), and then taking the difference, $h_{S}-h_{N}$. By taking the zonal average along the jet path (denoted here by angle brackets), the time series in Fig. 3 gives a measure for the overall intensity of the surface Kuroshio Extension jet. From Fig. 3, it is clear that the jet strength of the Kuroshio Extension underwent a low-frequency modulation over the past decade. The $\langle\delta h\rangle$ value was $\sim 0.65 \mathrm{~m}$ in late 1992 and had a decreasing trend over 
the period from 1993 to 1996 . The mean $\langle\delta h\rangle$ value in 1996 was only $0.45 \mathrm{~m}$, a $30 \%$ drop from the 1992 level. This decreasing trend in $\langle\delta h\rangle$ reversed after 1997 and the overall strength of the Kuroshio Extension in recent years has returned to the level of 1992/93.

The long-term modulation in the strength of the $\mathrm{Ku}$ roshio Extension can also be seen explicitly by comparing the SSH maps in different phases of the Kuroshio Extension jet strength. For example, Fig. 4a shows the SSH field in March 1993 when the Kuroshio Extension had a relatively large $\langle\delta h\rangle$ value. The coherent Kuroshio Extension jet in this case can be recognized to extend to the date line along $34^{\circ} \mathrm{N}$. In contrast, the jet structure of the Kuroshio Extension was weaker and more diffused in March 1996, when $\langle\delta h\rangle$ was relatively small (Fig. 4b). After the restrengthening of recent years, one can again identify the coherent jet structure of the $\mathrm{Ku}-$ roshio Extension extending to the date line in Fig. 4c (March 2000).

One consequence of this long-term modulation in the overall strength of the Kuroshio Extension jet is that the regional kinetic energy level also underwent a clear decadal modulation. Figure 5 shows the yearly averaged kinetic energy distributions estimated from the alongtrack SSH data by assuming geostrophy and the isotropic condition. As the SSH gradients are dominated by signals of the SSH anomalies, the kinetic energy distributions shown in Fig. 5 reflect largely the distributions of the mesoscale eddy field. The interannual trends found in the kinetic energy field are similar to those shown in Figs. 3 and 4. Specifically, the zonal penetration of the high kinetic energy band decreased persistently from 1993 to 1996 (Figs. 5a-d) and, over the entire Kuroshio Extension region, the kinetic energy level was at its minimum in 1996. Following 1997, the trend in kinetic energy level reversed and the high kinetic energy band expanded progressively eastward (Figs. 5e-j). Like the time-varying strength of the $\mathrm{Ku}-$ roshio Extension shown in Fig. 3, the kinetic energy level in years 2000-02 had similar magnitude and spatial patterns to those observed in 1993.

With the Kuroshio Extension jet subject to persistent baroclinic instability (e.g., Hurlburt et al. 1996), the correspondence between the interannual trends in the $\langle\delta h\rangle$ time series and that of the kinetic energy level is no surprise. A larger $\langle\delta h\rangle$ in Fig. 3 signifies a more intense zonal jet, whose larger surface transport and greater zonal penetration are likely to give rise to a higher level of eddy kinetic energy because of enhanced baroclinic instability. Since the large-scale changes in the mean and eddy field of the Kuroshio Extension region can exert a great influence on the regional SST field, which in turn may impact the overlying atmospheric circulation, a solid understanding of the causes for the observed changes in $\langle\delta h\rangle$ is clearly called for.

\section{Dynamic response of the Kuroshio Extension}

To clarify the causes for the low-frequency signals shown in Fig. 3, it is helpful to look into the along- stream development of the time-varying Kuroshio Extension jet. Figure 6 shows the anomalies of the SSH difference across the Kuroshio Extension jet, $\delta h^{\prime}$, as a function of time and longitude. Here, primes denote deviations from the time average. Although noisy due to the presence of the mesoscale eddy variability, the $\delta h^{\prime}$ signals, especially those associated with the interannual trends in $\langle\delta h\rangle$, have a consistent pattern: $\delta h^{\prime}$ anomalies tend to appear first in the downstream $\mathrm{Ku}-$ roshio Extension region and then propagate westward. This is the case for the large, negative $\delta h^{\prime}$ anomalies that resulted in the $\langle\delta h\rangle$ minimum of 1996 , and it is also true for the positive $\delta h^{\prime}$ anomalies that caused the increasing trend in $\langle\delta h\rangle$ following 1997 . From the $\delta h^{\prime}$ slopes in Fig. 6, the westward propagating speed of the $\delta h^{\prime}$ signals is found to be $\sim 0.04 \mathrm{~m} \mathrm{~s}^{-1}$ (denoted in the figure by a straight diagonal line). This estimated speed falls in the range of the phase speed of first-mode baroclinic Rossby waves in the latitude band of the Kuroshio Extension (e.g., Mizuno and White 1983; Qiu et al. 1991), suggesting a potential role played by baroclinic adjustment processes in carrying externally forced SSH signals from the east. Given the significant PDO-related changes in the surface wind stress field over the eastern North Pacific Ocean (recall Fig. 2), it is natural to ask to what extent the observed $\langle\delta h\rangle$ signal could be explained by the variability in the basinwide wind stress field.

To address this question quantitatively, we adopt in this study the 1/1/2-layer reduced-gravity model that governs the large-scale, baroclinic ocean response to surface wind forcing. Under the long-wave approximation, the linear vorticity equation of the model is

$$
\frac{\partial h}{\partial t}-c_{R} \frac{\partial h}{\partial x}=-\frac{g^{\prime} \mathbf{k} \cdot \boldsymbol{\nabla} \times \boldsymbol{\tau}}{\rho_{o} g f},
$$

where $h$ is the SSH of interest, $c_{R}$ is the speed of the long baroclinic Rossby waves, $g^{\prime}$ is the reduced gravity, $\rho_{o}$ is the reference density, $f$ is the Coriolis parameter, $\mathbf{k}$ is the unit vector in the vertical direction, and $\mathbf{k} \cdot \boldsymbol{\nabla}$ $X \boldsymbol{\tau}$ is the curl of the wind stress vector. Integrating Eq. (1) from the eastern boundary $\left(x_{e}\right)$ along the baroclinic Rossby wave characteristic, we have

$$
\begin{aligned}
& h(x, y, t) \\
& =h\left(x_{e}, y, t+\frac{x-x_{e}}{c_{R}}\right) \\
& \quad+\frac{g^{\prime}}{\rho_{o} g f c_{R}} \int_{x_{e}}^{x} \mathbf{k} \cdot \boldsymbol{\nabla} \times \boldsymbol{\tau}\left(x^{\prime}, y, t+\frac{x-x^{\prime}}{c_{R}}\right) d x^{\prime} .
\end{aligned}
$$

To hindcast the $h(x, y, t)$ field from Eq. (2), we use the monthly wind stress data from the NCEP reanalysis (Kalnay et al. 1996). The horizontal resolution of the NCEP data is $1.904^{\circ}$ lat $\times 1.875^{\circ}$ lon. Along the eastern boundary, $h\left(x_{e}, y, t\right)=0$ is assumed. Justification for 
(a) SSH field: 03/1993

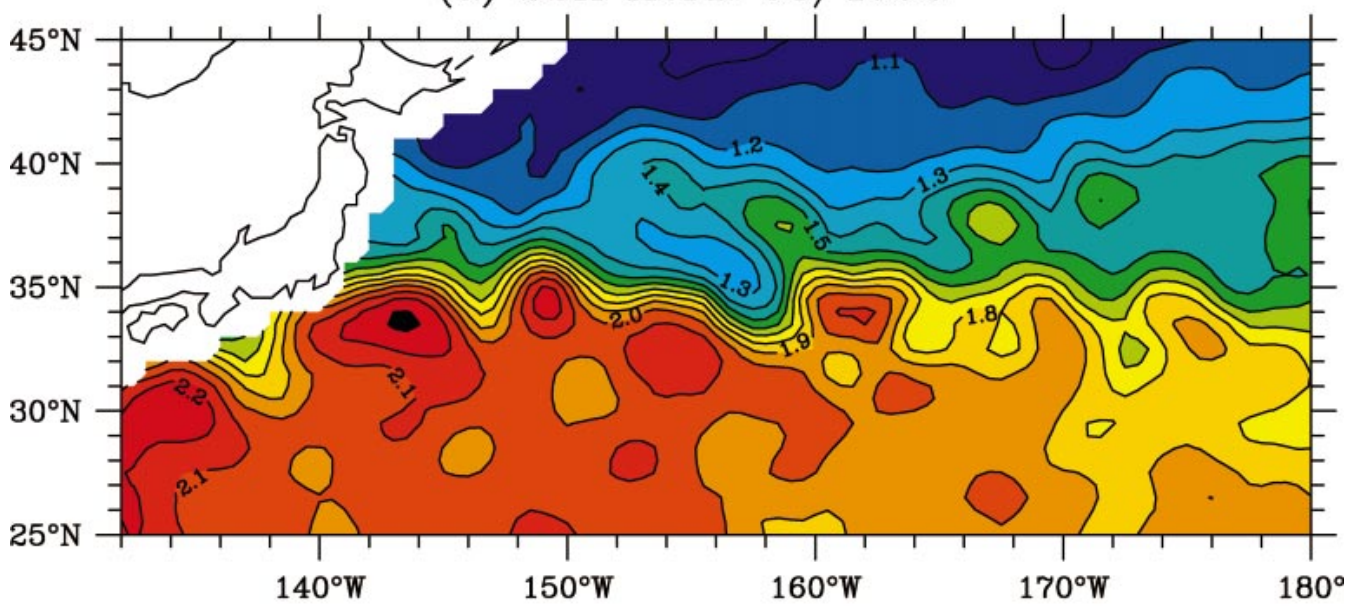

(b) SSH field: 03/1996

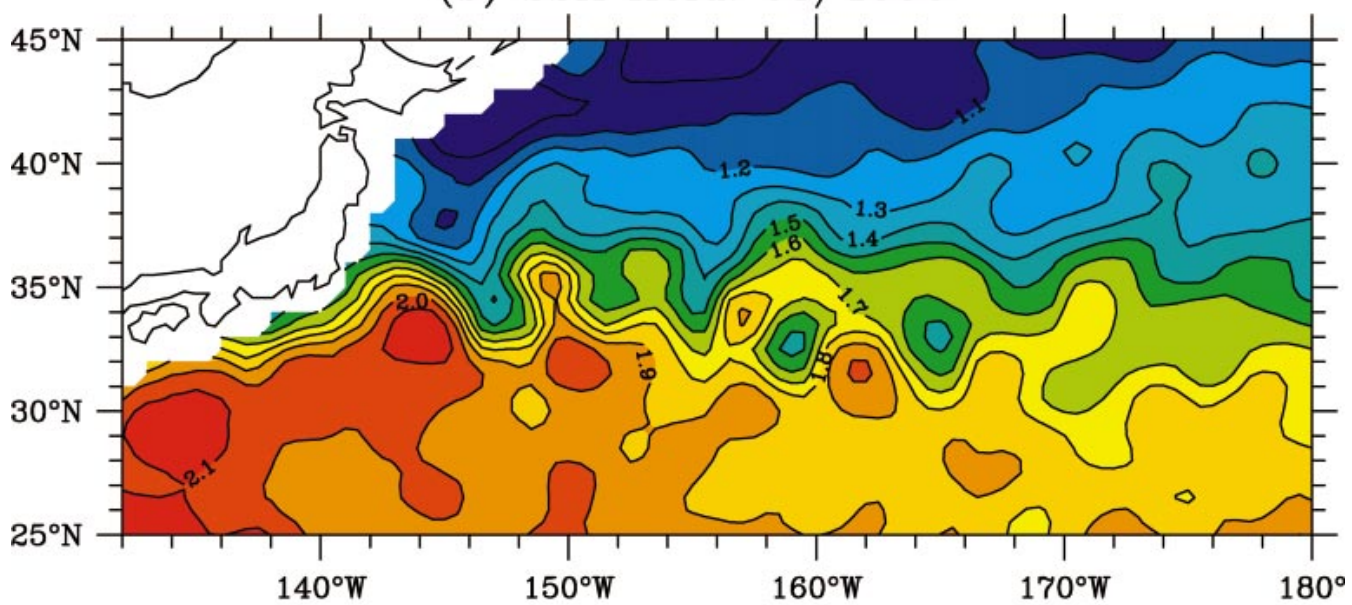

(c) SSH field: 03/2000

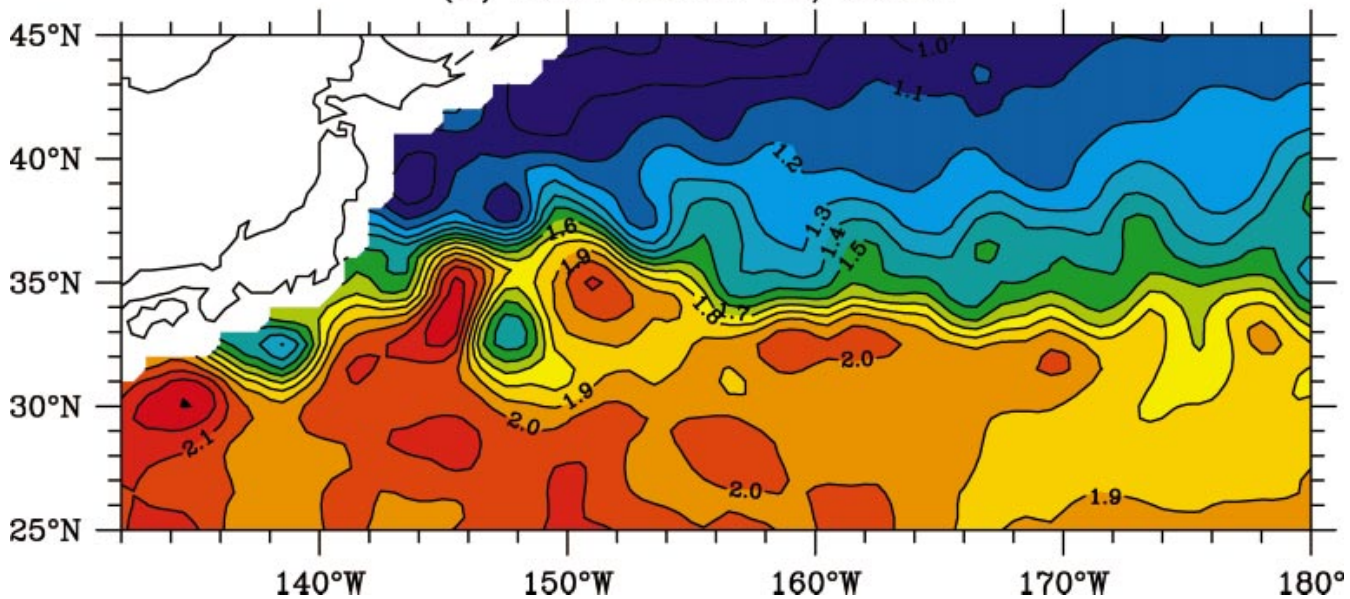

FIG. 4. Sea surface height fields in (a) Mar 1993, (b) Mar 1996, and (c) Mar 2000. 

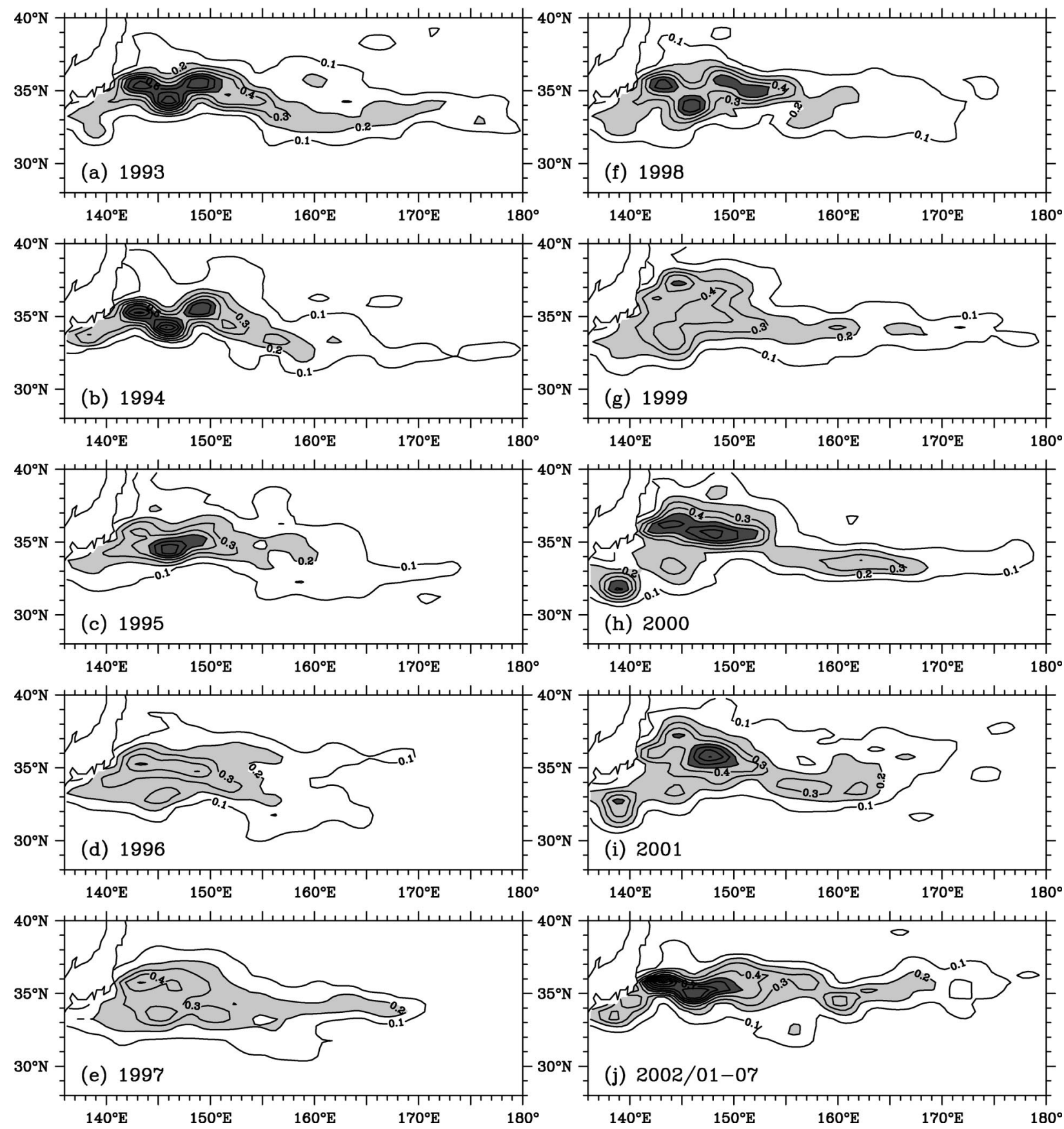

FIG. 5. Yearly averaged kinetic energy distributions estimated from the along-track absolute $\mathrm{SSH}$ data. Contour intervals are $0.1 \mathrm{~m}^{2} \mathrm{~s}^{-2}$. Light-shaded areas indicate energy levels greater than $0.2 \mathrm{~m}^{2} \mathrm{~s}^{-2}$ and dark-shaded areas indicate energy levels greater than $0.5 \mathrm{~m}{ }^{2} \mathrm{~s}^{-2}$.

this assumption follows Fu and Qiu (2002) who, by using the same reduced-gravity model and analyzing the T/P data, found that the forcing along the eastern boundary is of little importance in determining the large-scale SSH signals in the interior midlatitude North Pacific Ocean. For the latitude-dependent baroclinic Rossby wave speed $c_{R}$, we use the values shown in Fig. 7. These values are estimated by calculating autospectra of the T/P SSH anomaly data in the frequency-zonal wave- number space (e.g., Tai and White 1990) along each latitude of the wind stress curl grid. Similar $c_{R}$ values can be found in Fig. 14 of Fu and Chelton (2001). Notice that the Rossby wave speed at $32.4^{\circ} \mathrm{N}$ on the southern side of the Kuroshio Extension jet $\left(c_{R}=0.041 \mathrm{~m} \mathrm{~s}^{-1}\right)$ is nearly 2 times as fast as that on the northern side of the jet $\left(c_{R}=0.023 \mathrm{~m} \mathrm{~s}^{-1}\right.$ at $\left.38.1^{\circ} \mathrm{N}\right)$. This large change in $c_{R}$ is due not only to the difference in latitude $\left(c_{R} \propto\right.$ $f^{-2}$ and $\left.f_{N}^{2} / f_{S}^{2}=1.33\right)$, but also the difference in equiv- 


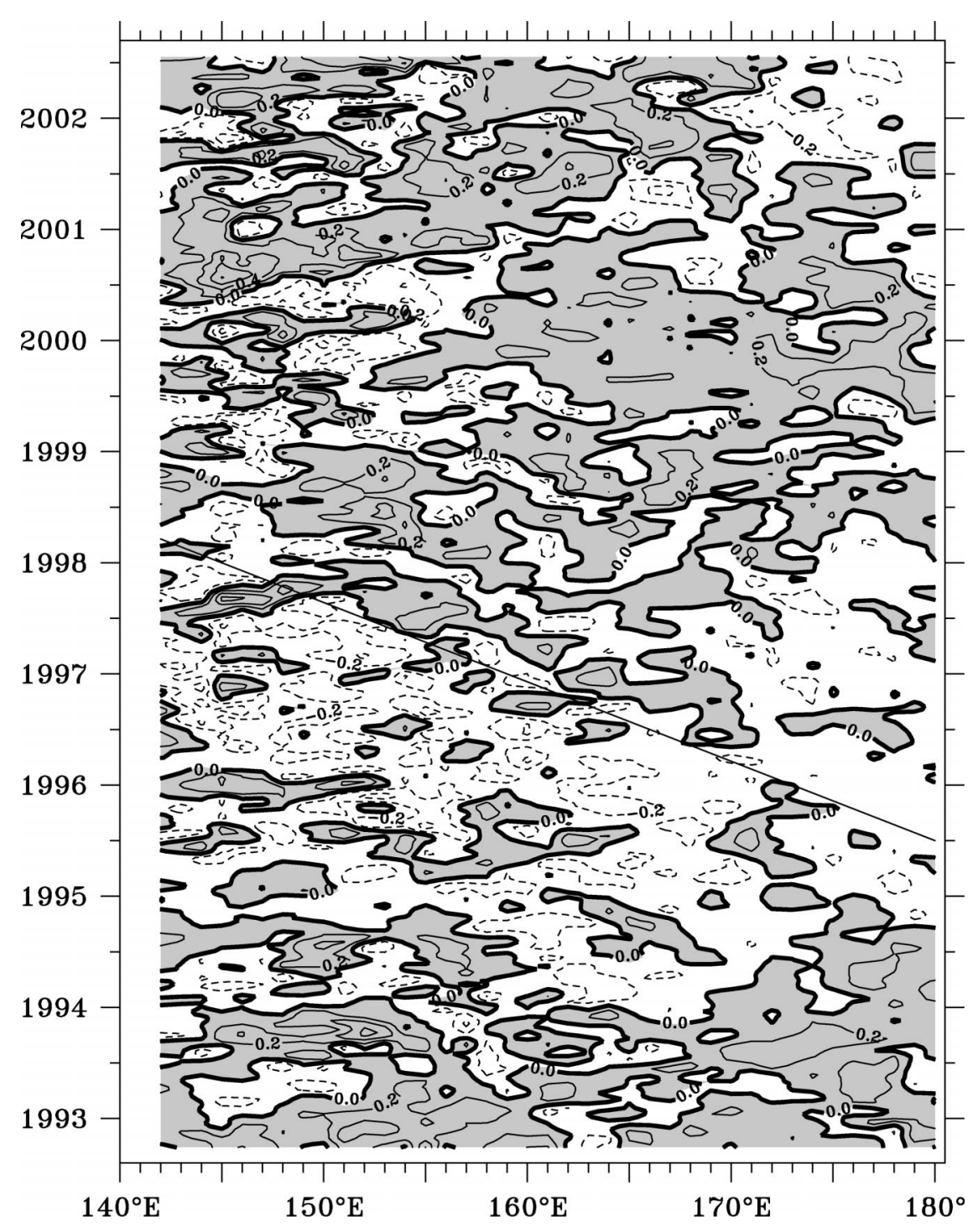

FIG. 6. SSH difference anomalies, $\delta h^{\prime}$, across the Kuroshio Extension jet as a function of time and longitude. Contour intervals are $0.2 \mathrm{~m}$ and shaded areas indicate positive $\delta h^{\prime}$ anomalies. The straight diagonal line denotes the westward propagating speed of $0.04 \mathrm{~m} \mathrm{~s}^{-1}$.

alent depth $H_{e}$ on the two sides of the Kuroshio Extension jet. $\left(H_{e}\right.$ is larger on the subtropical side of the jet than on the subpolar side.) As we will find below, this difference in $c_{R}$ plays a central role in determining the timescale of the Kuroshio Extension variability. Last, $g^{\prime}=0.027 \mathrm{~m} \mathrm{~s}^{-2}$ is used in Eq. (2) as the reduced gravity value.

Figure 8 compares the yearly averaged SSH anomaly fields from the T/P data (left column) with those calculated from Eq. (2) (right column). As the hindcast model only predicts the SSH changes that are driven by the time-varying surface wind stress signals, the comparison is likely to be unfavorable in regions where other dynamic processes, such as instability and eddy-mean flow interaction, contribute to the SSH signals. Aside from the detailed SSH structures in the vicinity of the
Kuroshio Extension path, Fig. 8 reveals that the hindcast model is able to reproduce many aspects of the observed $\mathrm{SSH}$ patterns favorably. For example, both the T/P data and the model show that the SSH field surrounding the Kuroshio Extension in 1993 is dominated by the presence of positive height anomalies (Fig. 8a). From 1994 to 1996 , both show a progressive, westward expansion of negative SSH anomalies south of the Kuroshio Extension jet (Figs. 8b-d). The westward expansion of these negative SSH anomalies gradually reduces the SSH difference across the Kuroshio Extension path and is responsible for the decreasing trend of $\langle\delta h\rangle$ shown in Fig. 3. In 1997, both the observed and modeled SSH fields are dominated by the presence of negative height anomalies (Fig. 8e) and the westward expansion of positive SSH anomalies south of the Kuroshio Extension 


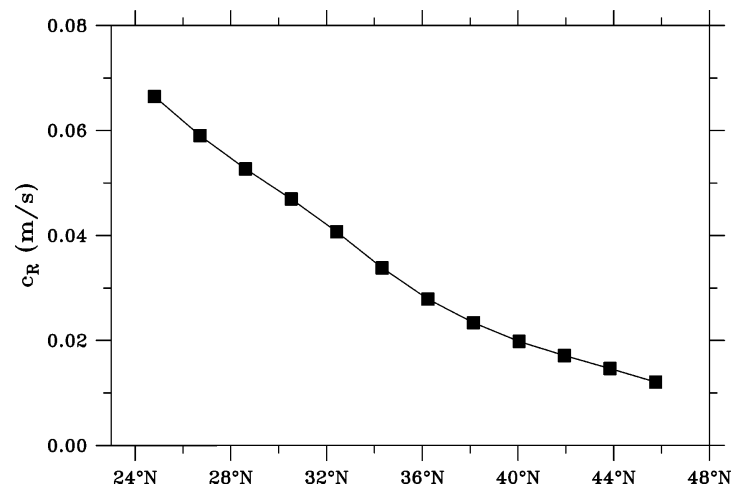

FIG. 7. Westward phase speed of first-mode baroclinic Rossby waves, $c_{R}$, as a function of latitude. The $c_{R}$ values are estimated from autospectra in the frequency-zonal wavenumber space of the T/P SSH data.

jet in the following years (Figs. 8f-i) is responsible for the increasing trend of $\langle\delta h\rangle$ after 1997.

To examine the geographical dependence of the model's hindcast skill, we plot in Fig. 9 the linear correlation coefficient $r$ between the yearly averaged T/P and modeled SSH fields. In general, the correlation between these two fields is high, $r>0.4$, in the downstream Kuroshio Extension region east of $\sim 160^{\circ}$ E. High correlation is also found south of the upstream Kuroshio Extension jet. The wind-driven model, however, fails to capture the SSH signals along the path of the upstream Kuroshio Extension and in the area to its north. The upstream Kuroshio Extension is where the highest eddy kinetic energy is observed (see Fig. 5), and the SSH signals here are likely controlled by processes of dynamic instability and the nonlinear interaction between eddies and the mean flow. Being adjacent to the Japan coast, the upstream Kuroshio Extension path and its SSH signals are also likely affected by changes in the inflow Kuroshio condition. The area north of the upstream Kuroshio Extension jet is where the subpolar gyre western boundary current, the Oyashio, converges from the north (Fig. 1). As noted by many previous investigators (e.g., Kawai 1972; Sekine 1988), this socalled "mixed water" region is frequented by anomalous intrusions of the subpolar waters; the governing dynamics here are clearly more complicated than the linear vorticity relation (1).

Since the variability in the North Pacific surface wind field has its center of action near $150^{\circ} \mathrm{W}$ (see Fig. 2a), it is important to clarify how the SSH changes found in the Kuroshio Extension region are related to the surface wind forcing centered in the eastern North Pacific. To do so, we show in Fig. 10 the time-longitude plot of the modeled $\mathrm{SSH}$ anomalies along $32.4^{\circ} \mathrm{N}$ versus those along $38.1^{\circ} \mathrm{N}$. These two latitudes straddle the Kuroshio Extension path west of the date line. While changing in amplitude along their journeys, most of the interannual SSH signals in the west at these two latitudes can be traced to their origins in the eastern North Pacific where the surface wind forcing is at a maximum. Notice that in the eastern basin, the wind-forced SSH anomalies at the two latitudes tend to have the same sign. For example, near $150^{\circ} \mathrm{W}$, the $\mathrm{SSH}$ anomalies at both latitudes change from predominantly positive to negative in 1992 and back to positive in 1997-98. This SSH shift in the eastern North Pacific near the center of the maximum wind forcing is a direct response to the local wind stress curl field (see Fig. 10c), with positive curl anomalies lowering the SSH and vice versa. Due to the different propagation speeds of the baroclinic Rossby waves at $32.4^{\circ}$ and $38.1^{\circ} \mathrm{N}$, however, Fig. 10 shows that the SSH signals arriving in the west no longer have the same sign. In fact, it is the fast-propagating, positive $\mathrm{SSH}$ anomalies along $32.4^{\circ} \mathrm{N}$ (generated by the negative $\mathbf{k} \cdot \boldsymbol{\nabla} \times \boldsymbol{\tau}$ anomalies after the 1998 PDO transition) catching up to the slow-moving, negative SSH anomalies along $38.1^{\circ} \mathrm{N}$ (generated by the positive $\mathbf{k} \cdot \boldsymbol{\nabla} \times$ $\boldsymbol{\tau}$ anomalies prior to the PDO transition) that cause the large $\langle\delta h\rangle$ across the Kuroshio Extension jet in recent years. Similarly, arrivals of the fast-propagating negative $\mathrm{SSH}$ anomalies along $32.4^{\circ} \mathrm{N}$ and the slow-moving positive SSH anomalies along $38.1^{\circ} \mathrm{N}$ are the cause for the small $\langle\delta h\rangle$ across the Kuroshio Extension jet around 1996. In this latter case, the negative SSH anomalies to the south are generated by the positive $\mathbf{k} \cdot \boldsymbol{\nabla} \times \boldsymbol{\tau}$ anomalies in 1992-95, whereas the positive SSH anomalies to the north are generated by the negative $\mathbf{k} \cdot \boldsymbol{\nabla} \times \boldsymbol{\tau}$ anomalies prior to 1992 (see Fig. 10c).

Given the success of the wind-driven reduced-gravity model in simulating the large-scale SSH anomaly signals over the $\mathrm{T} / \mathrm{P}$ period, it is of interest to extend the hindcast to a longer time period. In Fig. 11a, we plot the time series of $\left\langle\delta h^{\prime}\right\rangle$ based on Eq. (2) with the use of the NCEP monthly wind-stress curl data available from 1948 to 2001 . Here, $\left\langle\delta h^{\prime}\right\rangle$ is defined as the modeled SSH anomaly difference between $32.4^{\circ}$ and $38.1^{\circ} \mathrm{N}$ averaged from $142^{\circ} \mathrm{E}$ to $180^{\circ}$. Thus defined, $\left\langle\delta h^{\prime}\right\rangle$ provides a measure for the relative intensity of the zonal-mean Kuroshio Extension jet. From Fig. 11a, it is clear that the low-frequency modulation of the Kuroshio Extension jet detected by the T/P SSH measurements is by no means unique to the recent decade. Similar modulation can be seen to have occurred over the past 45 years. A spectral analysis of the $\left\langle\delta h^{\prime}\right\rangle$ time series reveals that the modulation of the Kuroshio Extension jet has a dominant timescale of $\sim 12$ yr (see Fig. 11b).

Since the wind stress curl forcing over the midlatitude oceans has largely a white frequency spectrum (e.g., Frankignoul et al. 1997), a question arising naturally is what determines this decadal timescale dominating the Kuroshio Extension jet modulation. In other words, does the ocean simply integrate passively the atmospheric wind forcing? Or, does the ocean dynamics play a more active role in selecting the decadal timescale shown in Fig. 11b? 
(a) T/P vs. modeled ssha: 1993

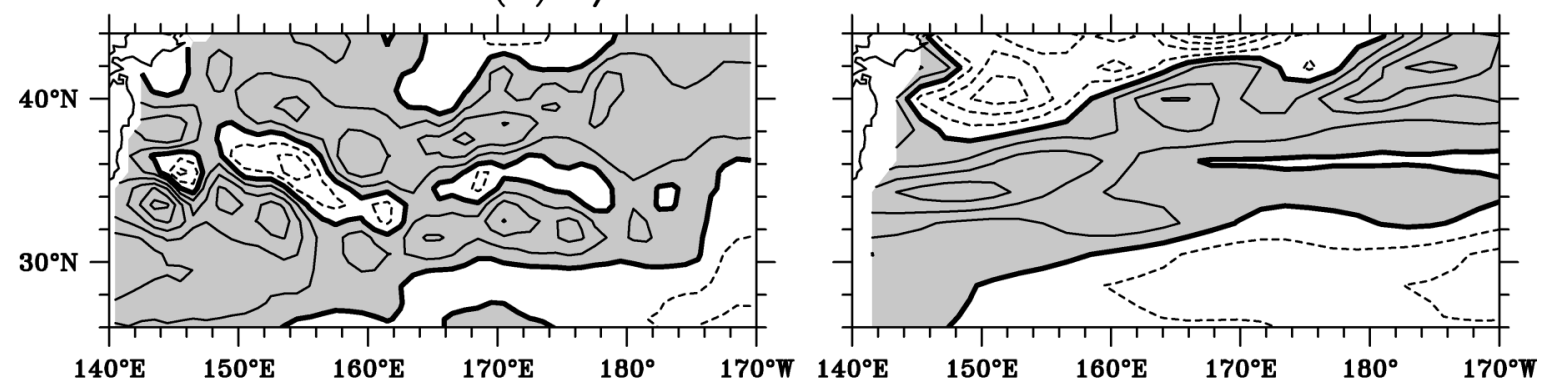

(b) T/P vs. modeled ssha: 1994

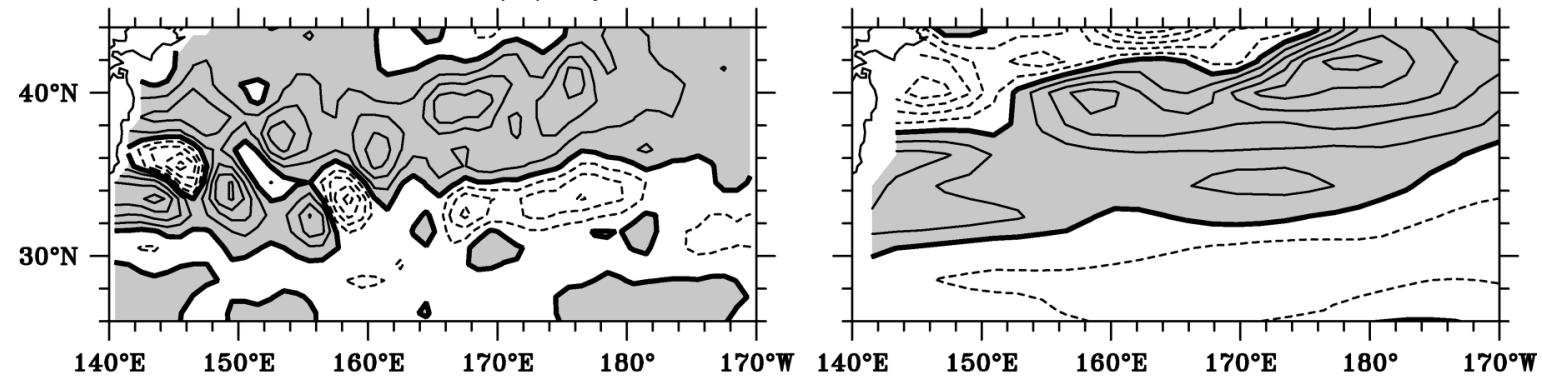

(c) T/P vs. modeled ssha: 1995

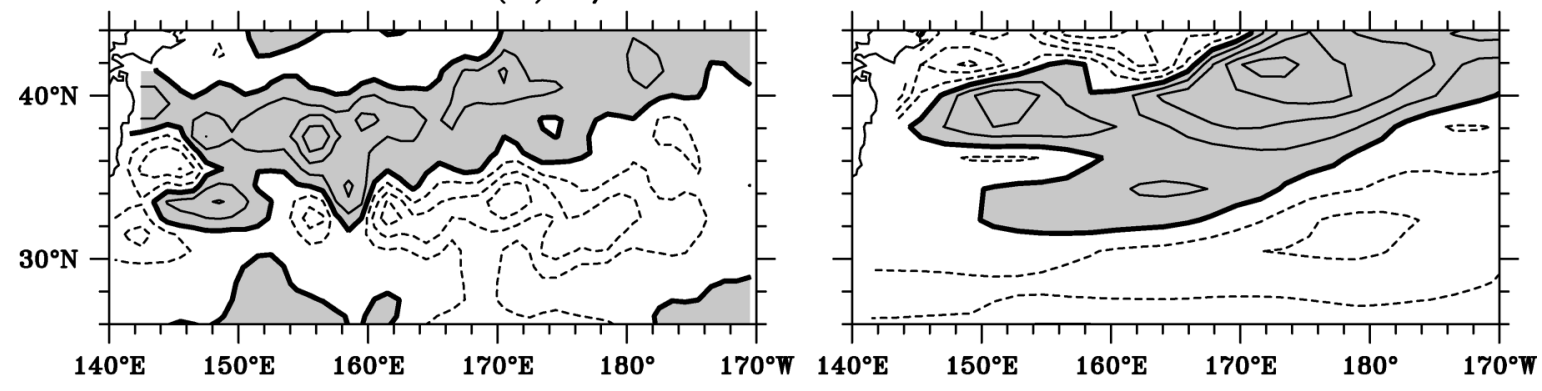

(d) T/P vs. modeled ssha: 1996

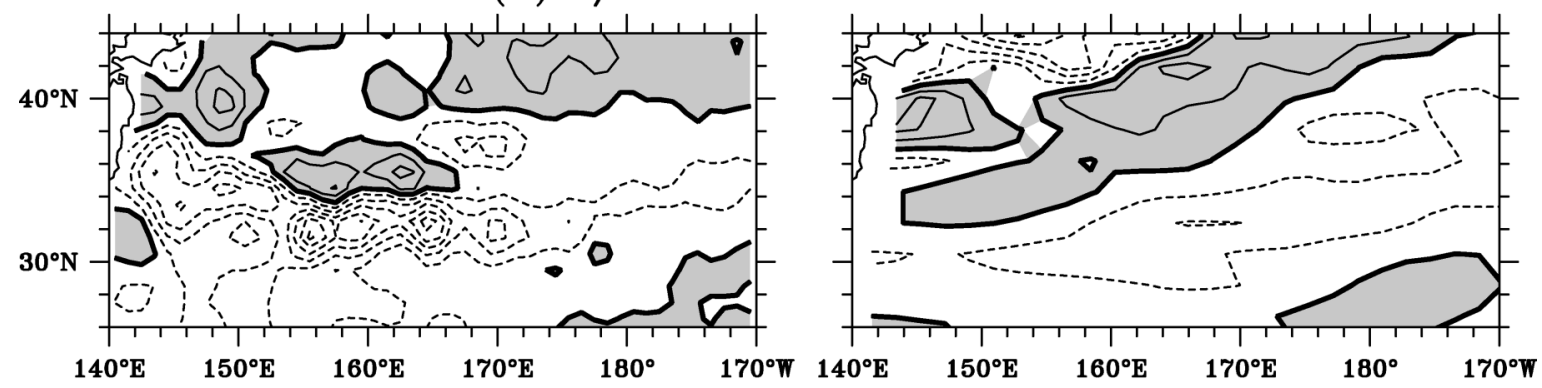

(e) T/P vs. modeled ssha: 1997

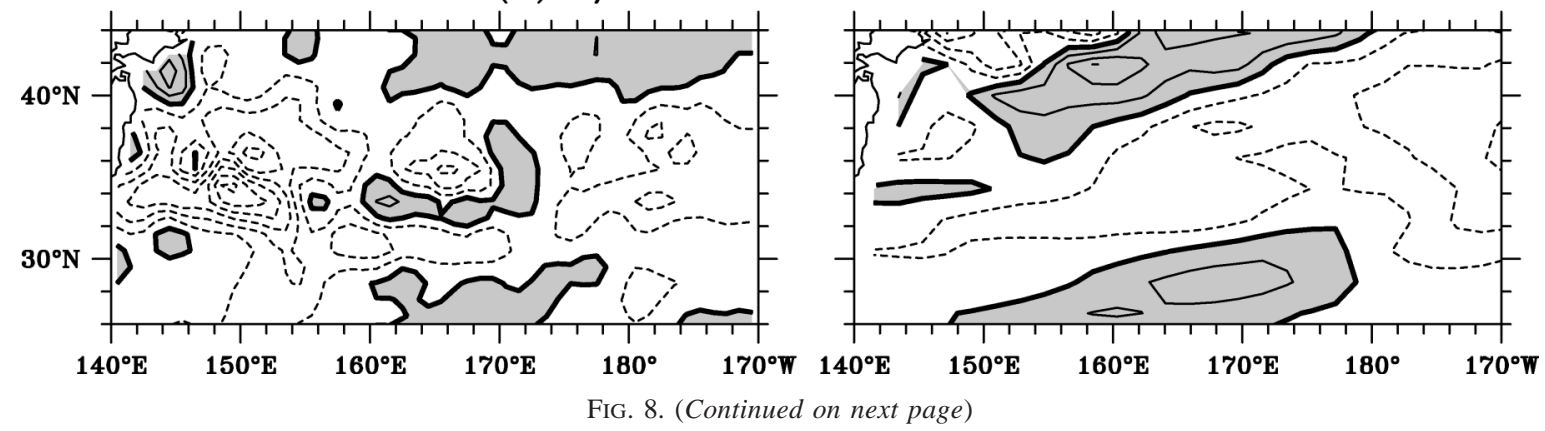


(f) T/P vs. modeled ssha: 1998
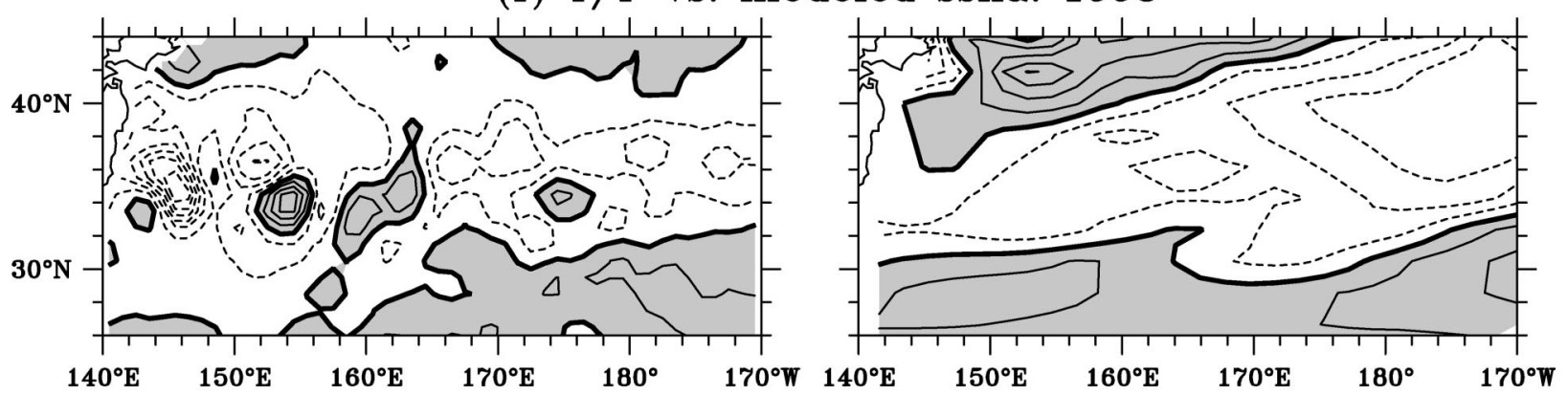

(g) T/P vs. modeled ssha: 1999
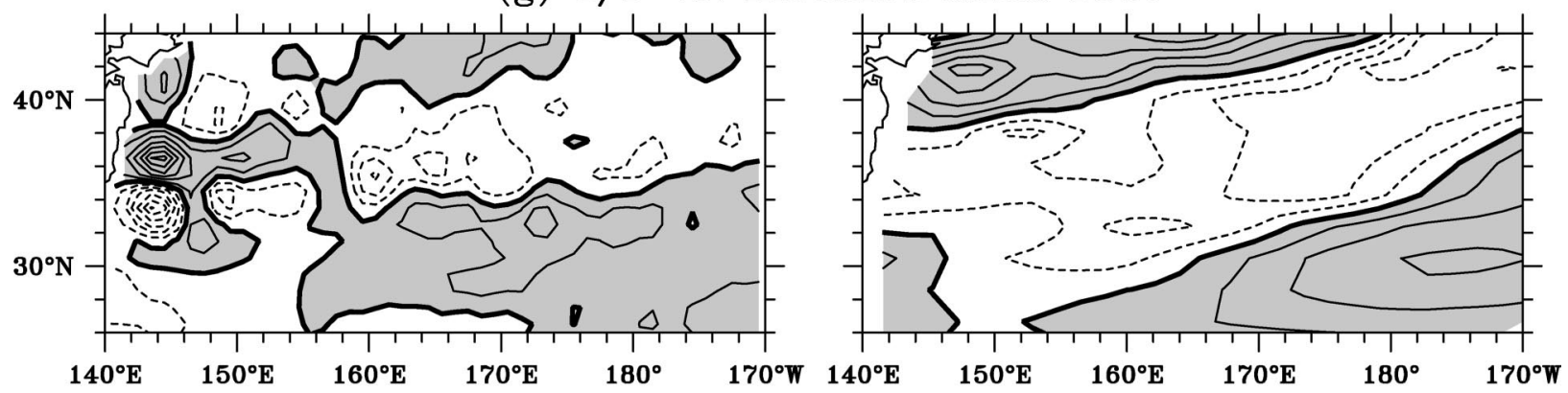

(h) T/P vs. modeled ssha: 2000
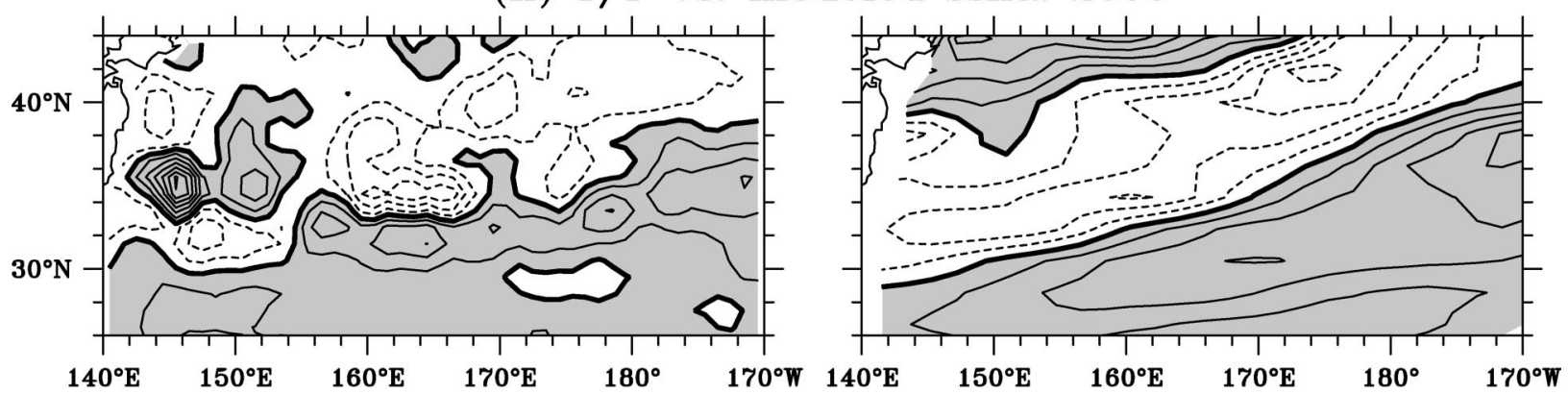

(i) T/P vs. modeled ssha: 2001
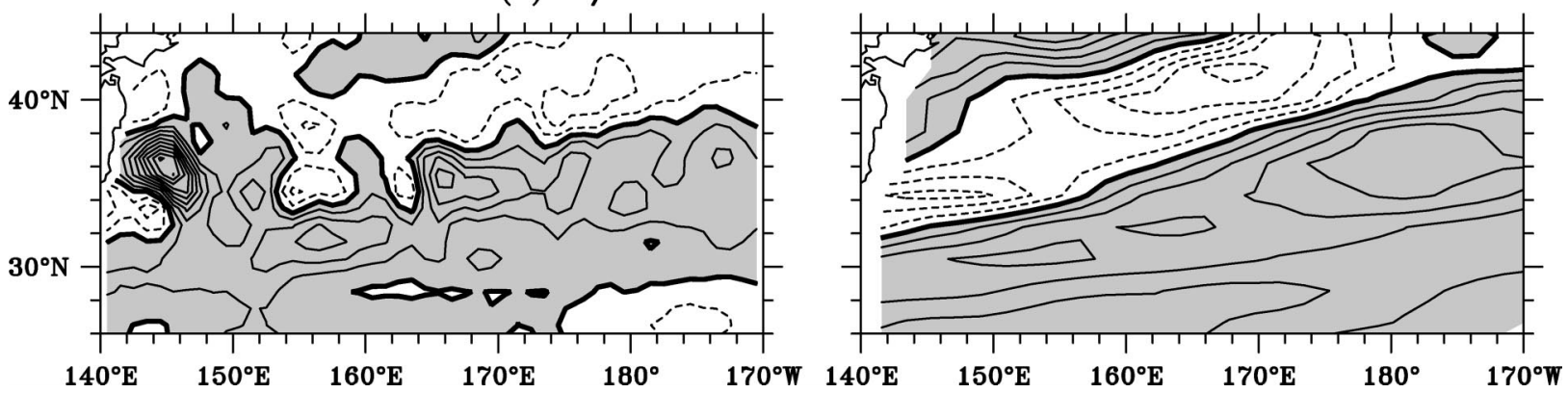

FIG. 8. Yearly averaged SSH anomalies from the T/P data (left column) vs those hindcast from the linear vorticity model forced by the NCEP monthly wind stress data (right column). Contour intervals are $0.04 \mathrm{~m}$ and shaded areas indicate positive SSH anomalies.

5. Kuroshio Extension modulation versus timescale selection

To answer this question, it is relevant to first point out that while the meridional scale of the wind stress curl anomalies in the eastern North Pacific is as large as $20^{\circ}$ in latitude, the forced oceanic signals in the west can have a much smaller meridional scale. This reduction in scale is due to the latitudinal dependence of the baroclinic Rossby wave speed and can be quantified as follows. Assume the wind forcing in the east is periodic with a period $T$ and let $W$ be the meridional length between latitudes A and B. As shown schematically in 


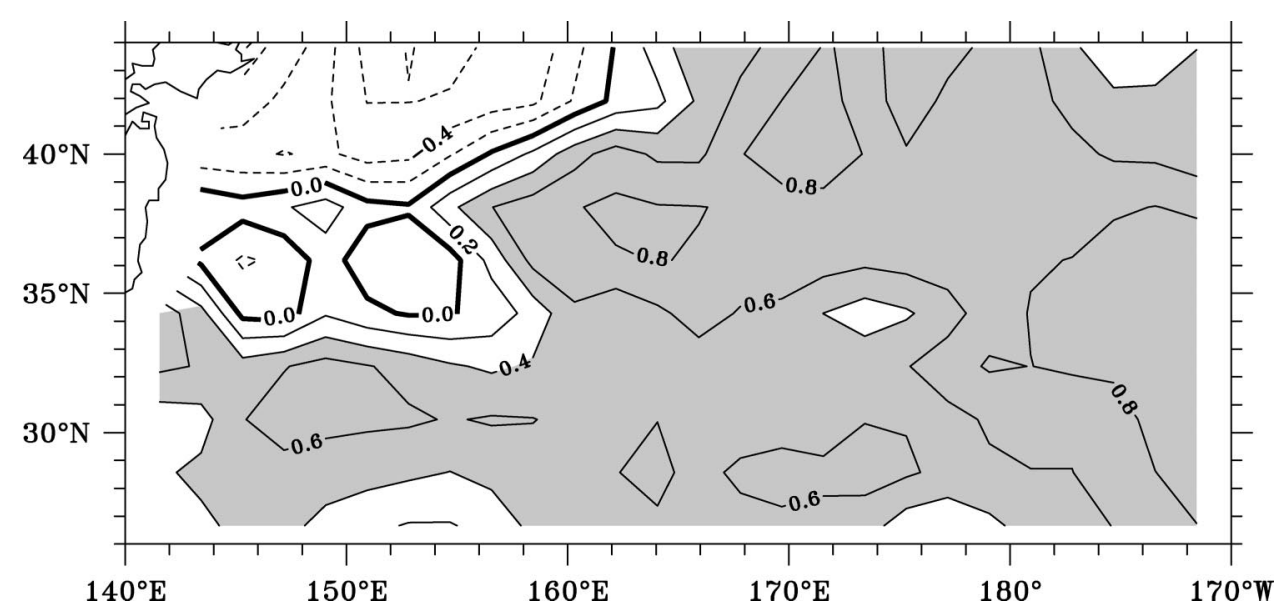

FIG. 9. Linear correlation coefficient $r$ between the yearly averaged SSH anomaly fields from the T/P data and those from the wind-driven hindcast model (see Fig. 8). Shaded areas indicate where the coefficient is higher than 0.4 .

Fig. 12, $W$ is located at a distance $X$ from the initial phase line (assumed to be meridional), and it separates the two bordering phase lines with a phase difference of $\pi$. If the baroclinic Rossby wave speeds at A and B are $c_{R \mathrm{~A}}$ and $c_{R \mathrm{~B}}$, respectively, it is easy to show

$$
\frac{T}{2}=X\left(\frac{1}{c_{R \mathrm{~B}}}-\frac{1}{c_{R \mathrm{~A}}}\right)
$$

Expanding $c_{R \mathrm{~B}}$ in a Taylor series around the latitude $\mathrm{A}$, we have (a) modeled SSHA along $32.4^{\circ} \mathrm{N}$

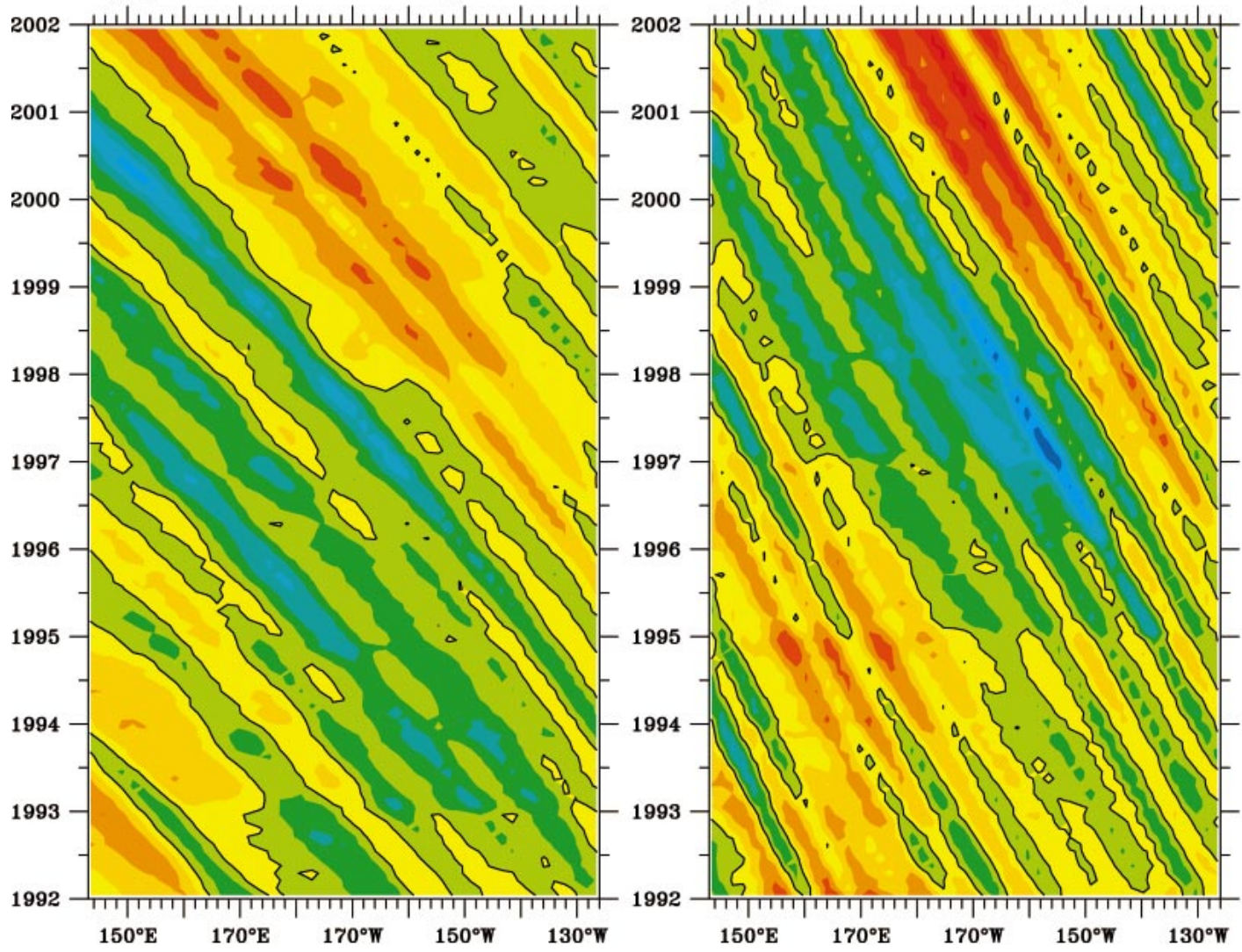

(c) $\mathbf{k} \cdot \nabla \times \tau^{\prime}$

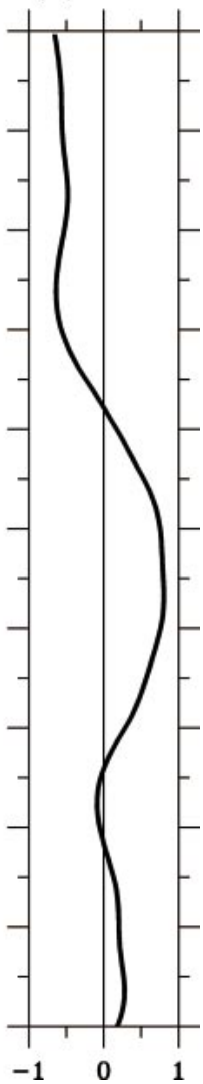

FIG. 10. SSH anomalies along (a) $32.4^{\circ}$ and (b) $38.1^{\circ} \mathrm{N}$ from the wind-driven hindcast model as a function of time and longitude. Contour intervals are $0.05 \mathrm{~m}$. (c) Time series of the weighting function for the first EOF mode of the wind stress curl anomalies. The time series is the same as that presented in Fig. 2a. 
(a) modeled $<\delta \mathrm{h}^{\prime}>$ across $\mathrm{KE}$ averaged in $142^{\circ} \mathrm{E}-180^{\circ}$

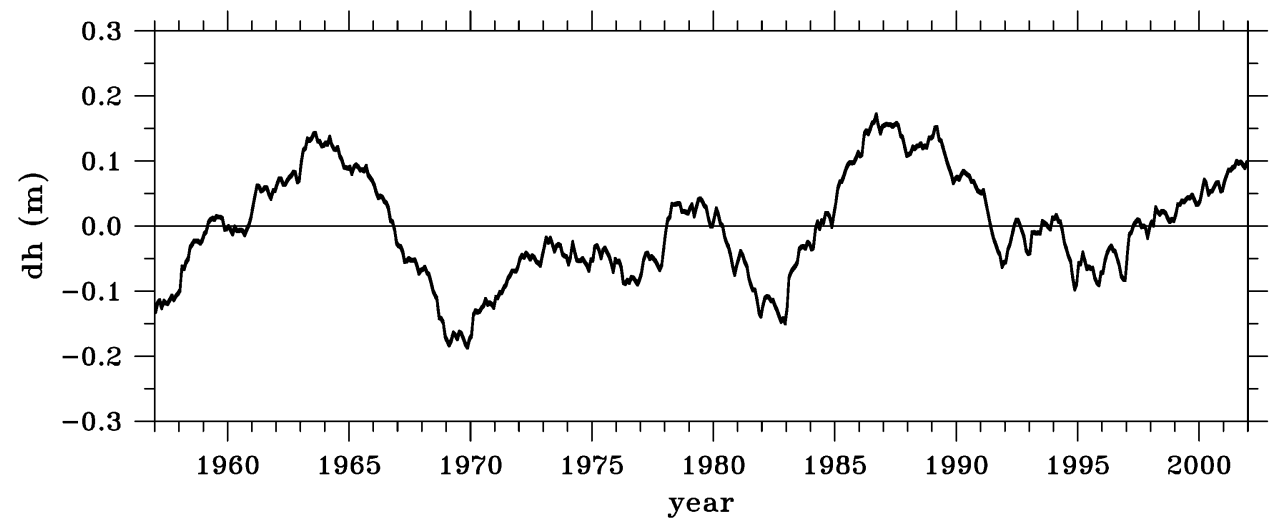

(b) frequency spectrum

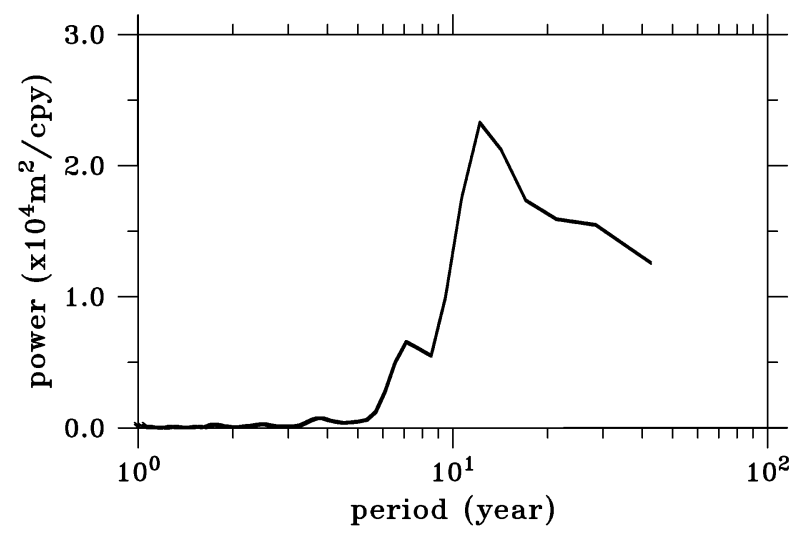

FIG. 11. (a) Time series of the zonally averaged SSH anomaly difference, $\left\langle\delta h^{\prime}\right\rangle$, between $32.4^{\circ}$ and $38.1^{\circ} \mathrm{N}$ across the Kuroshio Extension jet. The hindcast of Eq. (2) is based on the NCEP monthly wind stress curl data from 1948 to 2001. (b) Frequency spectrum of the time series shown in (a).

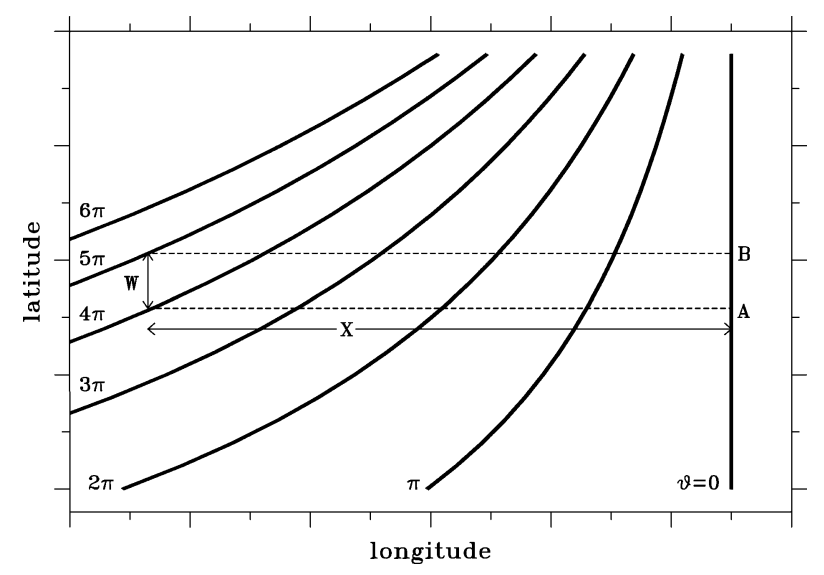

FIG. 12. Schematic showing the phase propagation of a monochromatic baroclinic Rossby wave initiated in the east. Each phase line is separated by $\pi$, and the initial phase line $(\theta=0)$ is assumed to be meridional. $W$ denotes the meridional scale between the two phase lines separated by $\pi$ at the distance $X$ west of the initial phase line.

$$
W=-\frac{T c_{R \mathrm{~A}}^{2}}{\left(2 X+T c_{R \mathrm{~A}}\right) \partial c_{R} /\left.\partial y\right|_{\mathrm{A}}} .
$$

Using the parameter values appropriate for the Kuroshio Extension region: $\mathrm{A}=35^{\circ} \mathrm{N}, c_{R \mathrm{~A}}=0.03 \mathrm{~m} \mathrm{~s}^{-1}, X=$ $4500 \mathrm{~km}$ (from $150^{\circ} \mathrm{W}$ to $160^{\circ} \mathrm{E}$ ), and $\partial c_{R} /\left.\partial y\right|_{\mathrm{A}}=-2.49$ $\times 10^{-8} \mathrm{~s}^{-1}$ (from Fig. 7), and assuming decadal wind forcing: $T=10 \mathrm{yr}$, we find $W=5.6^{\circ}$ lat. This estimated $W$ value agrees well with the meridional scales of the SSH anomalies found both in the model and the T/P data (see Fig. 8). With this shrinking of the meridional scale in the west, ${ }^{1}$ the decadal variations in the broadscale wind forcing of the eastern North Pacific become highly effective in modulating the strength of the zonally aligned Kuroshio Extension jet.

That the PDO-related surface wind stress forcing should produce an effect on the Kuroshio Extension

\footnotetext{
${ }^{1}$ Validity of the long-wave approximation requires $W \gg \pi L_{R}$, where $L_{R}$ is the baroclinic Rossby radius of deformation. Because $L_{R}$ $\simeq 35 \mathrm{~km}$ in the region of our interest (see Fig. 6 in Chelton et al. 1998), this "smaller" meridional scale $W=616 \mathrm{~km}$ is still much larger than $\pi L_{R}$.
} 

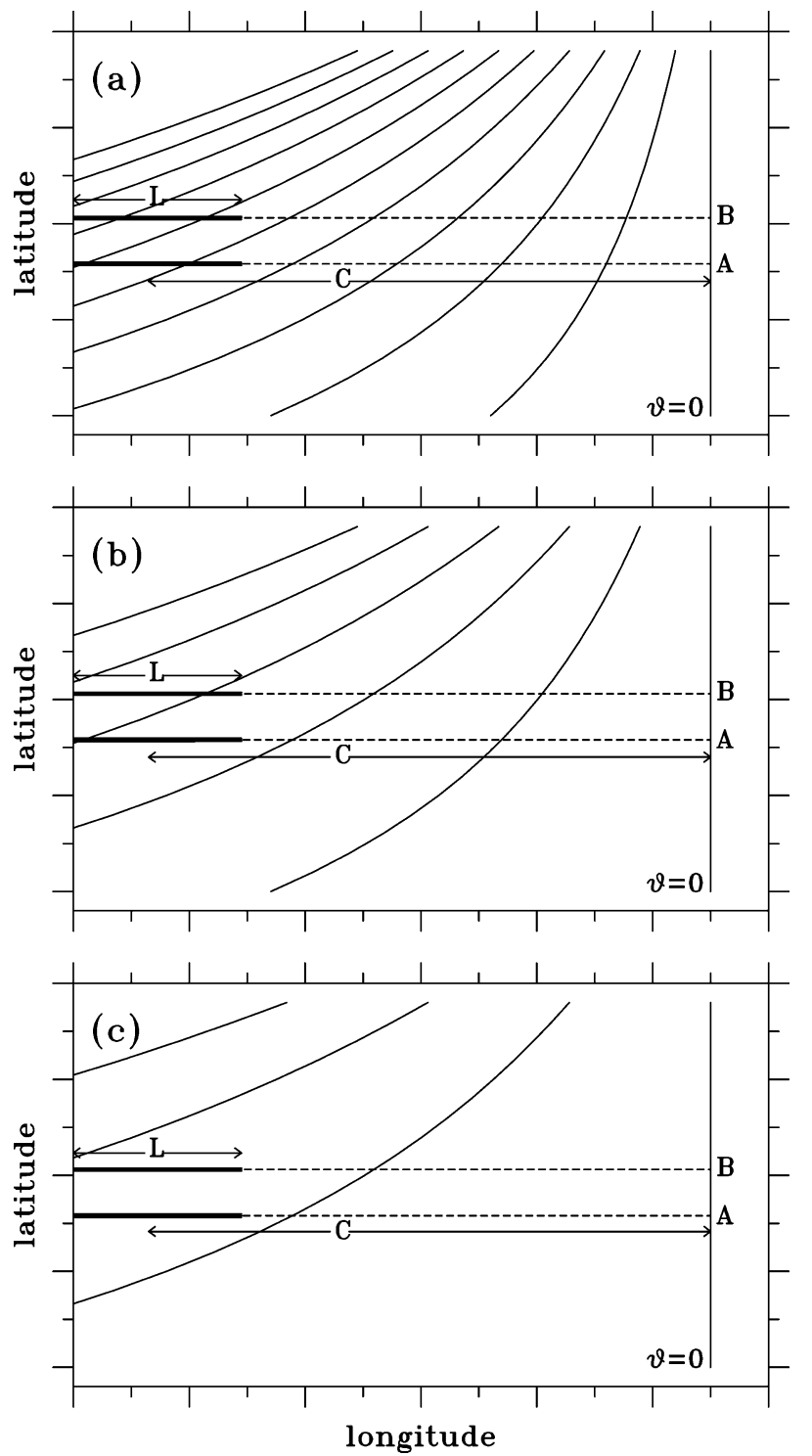

FIG. 13. Schematics showing the SSH phase maps under a monochromatic wind forcing in the east. The forcing period is short in (a), intermediate in (b), and long in (c). In the schematic, $L$ denotes the length of the boundary jet, $C$ is the distance from the forcing to the center longitude of the jet, and A and B denote the southern and northern latitudes bounding the jet, respectively. Each phase contour is separated by $\pi$ and the initial phase line $(\theta=0)$ is assumed to be meridional.

region on the scale of the jet width suggests more than a coincidental relation between the two. In fact, the magnitude of the wind-induced SSH difference across the Kuroshio Extension jet, $\left\langle\delta h^{\prime}\right\rangle$, is very sensitive to the period of the wind stress curl forcing. As shown schematically in Fig. 13a, forcing with a short wave period (hence, a short wavelength) would be ineffective at producing a large $\left\langle\delta h^{\prime}\right\rangle$ because averaging $\delta h^{\prime}$ along the zonal jet cancels out alongstream SSH anomalies of opposite signs. Likewise, forcing with a too-long wave period (Fig. 13c) would encompass the entire zonal jet with SSH anomalies of similar phase, resulting again in small $\left\langle\delta h^{\prime}\right\rangle$.

To quantify the dependence of $\left\langle\delta h^{\prime}\right\rangle$ on the forcing period and other physical parameters, it is useful to consider Eq. (1) as a stochastic forcing problem (Hasselmann 1976; Frankignoul and Hasselmann 1977):

$$
\frac{\partial h^{\prime}}{\partial t}-c_{R} \frac{\partial h^{\prime}}{\partial x}=F(x) W(t)
$$

where the time-varying function $W(t)$ has a white frequency spectrum. For simplicity, let $F(x)=\delta\left(x-x_{o}\right)$ (namely, the forcing is localized at $x=x_{o}$ ) and, without loss of generality, we set $x_{o}=0$. A more realistic form of $F(x)$ will be considered later on. West of $x=0$, the forced SSH anomaly field is simply

$$
\begin{aligned}
h^{\prime}(x, t) & =\frac{1}{c_{R}} \int_{x}^{0} F\left(x^{\prime}\right) W\left(t+\frac{x-x^{\prime}}{c_{R}}\right) d x^{\prime} \\
& =\frac{1}{c_{R}} W\left(t+\frac{x}{c_{R}}\right) .
\end{aligned}
$$

Averaging $h^{\prime}$ over the jet length $L$ along latitude A (see Fig. 13),

$$
\left\langle h_{\mathrm{A}}^{\prime}\right\rangle(t)=\frac{1}{L} \int_{-C-L / 2}^{-C+L / 2} \frac{1}{c_{R \mathrm{~A}}} W\left(t+\frac{x}{c_{R \mathrm{~A}}}\right) d x,
$$

and taking the Fourier transform, we obtain

$$
\left\langle\widehat{h_{\mathrm{A}}^{\prime}}\right\rangle(\omega)=\frac{2}{\omega L} \hat{W}(\omega) \sin \left(\frac{\omega L}{2 c_{R \mathrm{~A}}}\right) \exp \left(\frac{i \omega C}{c_{R \mathrm{~A}}}\right),
$$

where $C$ is the distance from the forcing to the longitudinal center of the zonal jet and $\hat{W}(\omega)$ is the Fourier transform of $W(t)$. A similar expression can be written for $\left\langle\widehat{h_{\mathrm{B}}^{\prime}}\right\rangle(\omega)$ by replacing $c_{R \mathrm{~A}}$ with $c_{R \mathrm{~B}}$ in Eq. (7).

Taking the SSH difference across the zonal jet and assuming white noise forcing (i.e., $|\hat{W}(\omega)|^{2}=1$ ), we find the power spectrum for $\left\langle\delta h^{\prime}\right\rangle$ as follows:

$$
\begin{aligned}
\left|\left\langle\widehat{\delta h^{\prime}}\right\rangle(\omega)\right|^{2}=\frac{T^{2}}{\pi^{2} L^{2}} & \sin ^{2}\left(\frac{\pi L}{T c_{R \mathrm{~A}}}\right)+\sin ^{2}\left(\frac{\pi L}{T c_{R \mathrm{~B}}}\right) \\
& -2 \sin \left(\frac{\pi L}{T c_{R \mathrm{~A}}}\right) \sin \left(\frac{\pi L}{T c_{R \mathrm{~B}}}\right) \\
& \left.\times \cos \left(\frac{2 \pi C}{T c_{R \mathrm{~B}}}-\frac{2 \pi C}{T c_{R \mathrm{~A}}}\right)\right] .
\end{aligned}
$$

In Eq. (8), $2 \pi C / T c_{R \mathrm{~B}}-2 \pi C / T c_{R \mathrm{~A}}$ denotes the phase difference between the two sides of the jet at the jet's center longitude, $x=-C$. When $2 \pi C / T c_{R \mathrm{~B}}-2 \pi C / T c_{R \mathrm{~A}}$ $=n \pi$ with $n$ being an odd integer, the SSH anomalies across the jet at $x=-C$ have opposite signs. Although this may hint at a maximum in $\left|\left\langle\widehat{\delta h^{\prime}}\right\rangle\right|^{2}$, the actual power spectrum of Eq. (8) is more complicated because of the averaging over the jet length. Notice that, in the 
high-frequency forcing limit, the power spectrum has an upper bound:

$$
\left|\left\langle\widehat{\delta h^{\prime}}\right\rangle(\omega)\right|^{2} \leq \frac{4 T^{2}}{\pi^{2} L^{2}}
$$

which decreases with decreasing $T$. On the other hand, in the low-frequency forcing limit (i.e., when $T$ is much longer than the transit time by baroclinic Rossby waves over the distances $C$ and $L$ ), Eq. (8) simplifies to

$$
\left|\left\langle\widehat{\delta h^{\prime}}\right\rangle(\omega)\right|^{2} \simeq\left(1+\frac{4 \pi^{2} C^{2}}{c_{R \mathrm{~B}} c_{R \mathrm{~A}} T^{2}}\right)\left(\frac{1}{c_{R \mathrm{~B}}}-\frac{1}{c_{R \mathrm{~A}}}\right)^{2},
$$

which decreases with increasing $T$. Clearly, there is an optimum value of $T$ between these two limits for which $\left|\left\langle\widehat{\delta h^{\prime}}\right\rangle\right|^{2}$ is a maximum.

In Fig. 14, we plot the power spectra of Eq. (8) as a function of the forcing period $T$. Solid lines (identical in Figs. $14 \mathrm{a}-\mathrm{c}$ ) show the result when the parameter values are chosen appropriate for the midlatitude North Pacific: $L=40^{\circ}$ (from $140^{\circ} \mathrm{E}$ to $180^{\circ}$ ), $C=50^{\circ}$ (at $160^{\circ} \mathrm{E}$ relative to the maximum forcing at $150^{\circ} \mathrm{W}$ ), A $=32.4^{\circ} \mathrm{N}$, and $\mathrm{B}=38.1^{\circ} \mathrm{N}$. With these nominal values, the maximum modulation in $\left\langle\delta h^{\prime}\right\rangle$ occurs when $T \simeq 10$ yr. Modulation in $\left\langle\delta h^{\prime}\right\rangle$ is ineffective when $T<5 \mathrm{yr}$, and the spectral power also decreases rapidly when $T$ exceeds $20 \mathrm{yr}$.

Notice that this "preferred" forcing period is not very sensitive to the detailed chosen parameter values. For example, Fig. 14a compares the results when the nominal zonal length of the jet, $L=40^{\circ}$, is changed to either $50^{\circ}$ or $30^{\circ}$ (the other parameters are kept at their nominal values). Although the maximum responding period shifts with changing $L$ values, the range of this shift is relatively small, about $\pm 2 \mathrm{yr}$. That the preferred forcing period lengthens with increasing $L$ is because averaging over progressively longer values of $L$ cancels out the phase extremes of progressively longer waves. At the low-frequency forcing limit, Fig. 14a shows that $\left|\left\langle\widehat{\delta h^{\prime}}\right\rangle\right|^{2}$ becomes independent of $L$, a result consistent with Eq. (10). The preferred forcing period, as shown in Fig. 14b, is also relatively insensitive to deviations from the chosen value of $C$. This is so because for the parameter values of our interest, phase lines of the SSH anomalies in the west are nearly zonal, making changes in $C$ inconsequential. For $T \geq 10 \mathrm{yr}$, Fig. 14b shows that the spectral power increases with increasing $C$ [see Eq. (10)], suggesting that forcing farther to the east is more effective in inducing large $\left\langle\delta h^{\prime}\right\rangle$ because the phase lines become increasingly better aligned with the zonal averaging box. Figure 14c compares the cases when the latitudes bounding the jet $(\mathrm{A}, \mathrm{B})$ are changed from $\left(32.4^{\circ}, 38.1^{\circ} \mathrm{N}\right)$ to either $\left(34.3^{\circ}, 38.1^{\circ} \mathrm{N}\right)$ or $\left(32.4^{\circ}\right.$, $\left.36.2^{\circ} \mathrm{N}\right)$. The preferred forcing period remains near 10 $\mathrm{yr}$ in the $\left(34.3^{\circ}, 38.1^{\circ} \mathrm{N}\right)$ case, whereas it shifts to $\sim 8$ $\mathrm{yr}$ in the $\left(32.4^{\circ}, 36.2^{\circ} \mathrm{N}\right)$ case. This shift to a shorter preferred period is due to the fact that the zonal jet in this latter case is located at a more southerly latitude,
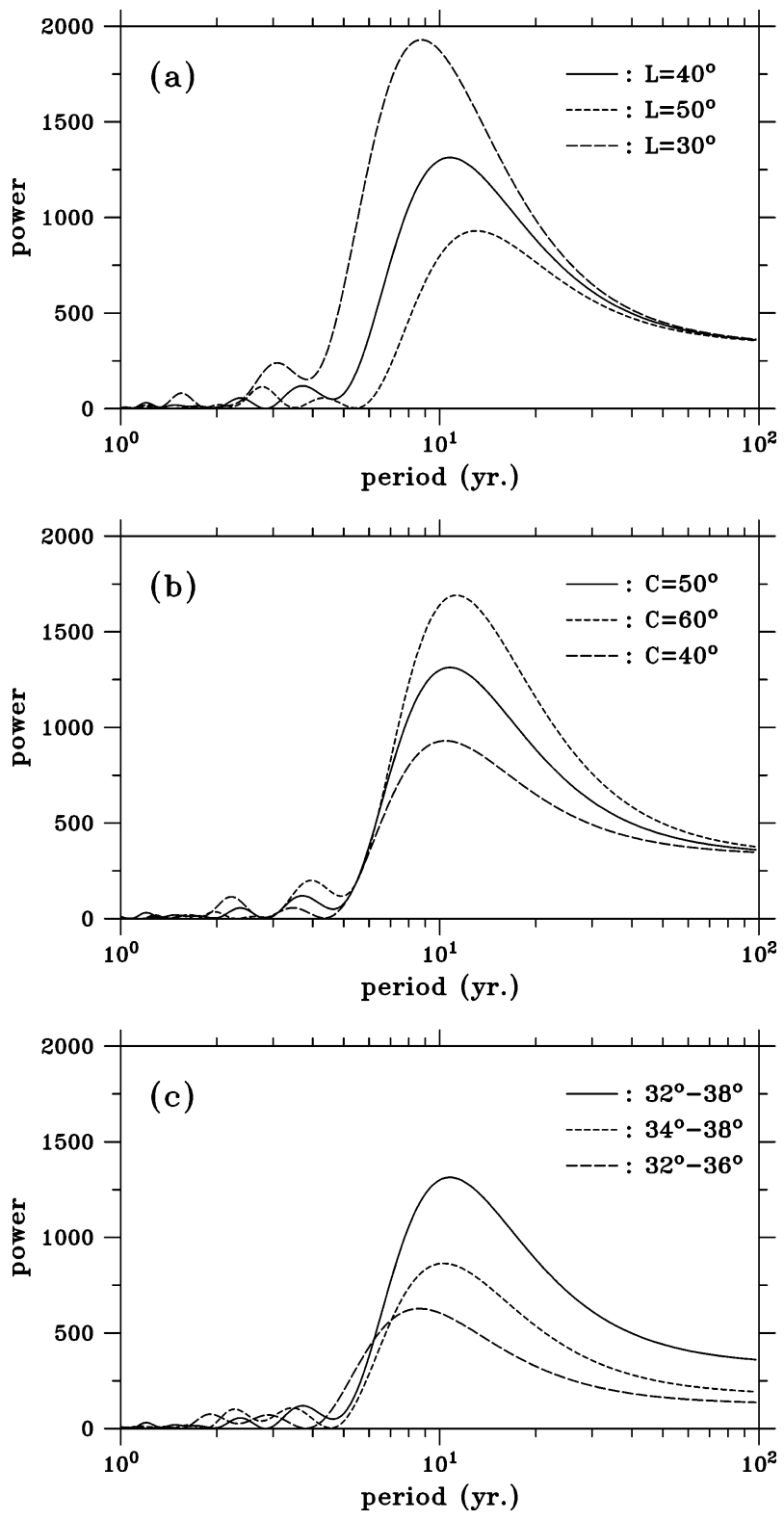

FIG. 14. Power spectra of $\left|\left\langle\widehat{\delta h^{\prime}}\right\rangle\right|^{2}$, defined in Eq. (8), as a function of the forcing period $T$. Solid lines show the result with parameter values most appropriate for the North Pacific Ocean: $L=40^{\circ}, C=$ $50^{\circ}, \mathrm{A}=32.4^{\circ} \mathrm{N}$, and $\mathrm{B}=38.1^{\circ} \mathrm{N}$. Dashed lines show the results when (a) the jet length $L$ is adjusted, (b) the distance between the forcing and the longitudinal center of the jet $C$ is adjusted, and (c) the latitudes bounding the jet, $\mathrm{A}$ and $\mathrm{B}$, are adjusted.

which shortens the required baroclinic adjustment time. Under the low-frequency forcing, the two cases with a narrower jet width have a smaller spectral power than that in the nominal case. As shown in Eq. (10), this is because $\left|\left\langle\widehat{\delta h^{\prime}}\right\rangle\right|^{2}$ in this limit is proportional to $c_{R \mathrm{~A}}-$ $c_{R \mathrm{~B}}$, which is smaller for a more narrowly defined jet.

For tractability of analytical expressions, we have in the above assumed the spatial function of the forcing in Eq. (5) to be a $\delta$ function. While centered over the 


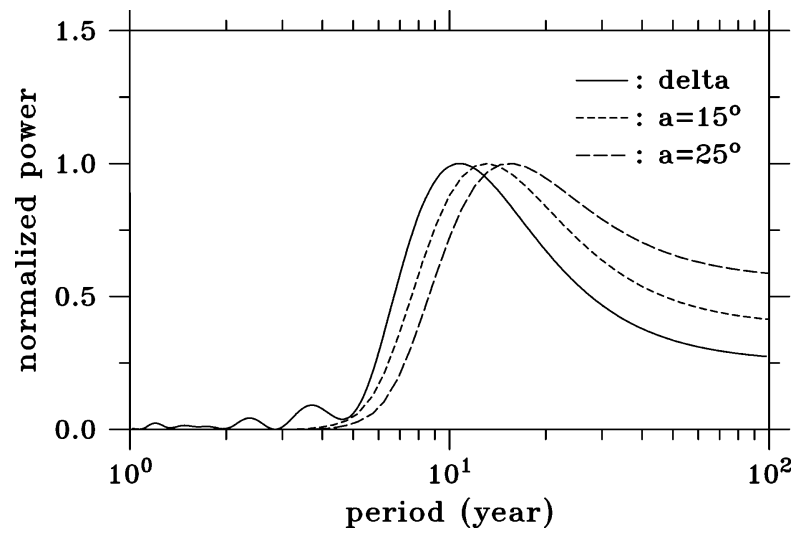

FIG. 15. Power spectra under the forcing with the spatial function $F(x)=\delta\left(x-x_{o}\right)$ vs $F(x)=\exp \left[-\left(x-x_{o}\right)^{2} / a^{2}\right]$. In the latter case, $a=15^{\circ}$ and $a=25^{\circ}$ are used, respectively. For comparison, the spectral power in each case has been normalized by its respective maximum value. In all cases, $L=40^{\circ}, C=50^{\circ}, \mathrm{A}=32.4^{\circ} \mathrm{N}$, and $\mathrm{B}=38.1^{\circ} \mathrm{N}$ are used

eastern North Pacific Ocean, Fig. 2a shows that the wind stress curl forcing does have a sizable width in longitude. To examine how this "broad width" forcing may alter the spectral pattern of $\left|\left\langle\widehat{\delta h^{\prime}}\right\rangle\right|^{2}$, it is useful to assume that $F(x)$ has a more realistic Gaussian distribution:

$$
F(x)=\exp \left[-\left(x-x_{o}\right)^{2} / a^{2}\right],
$$

where $a$ denotes the longitudinal $e$-folding scale of the forcing. For the North Pacific case (Fig. 2a), $a$ is in the range of $15^{\circ}-25^{\circ}$. In Fig. 15, we compare the power spectrum shapes when $a$ is, respectively, $15^{\circ}$ and $25^{\circ}$, with that produced by the $\delta$-function forcing. In all three cases, $\mathrm{A}, \mathrm{B}, C$, and $L$ are fixed at their nominal values appropriate for the North Pacific. In general, as $a$ lengthens, the "preferred" timescale tends to shift to a longer period and its spectral power relative to the lower-frequency signals tends to decrease. (The normalized curves in Fig. 15 represent different values of integrated wind stress, and so only relative spectral shapes are significant.) It is interesting to note that the spectral shape with $a=15^{\circ}$ bears a good resemblance to the $\left|\left\langle\delta h^{\prime}\right\rangle\right|^{2}$ shape of Fig. 11b, in which the strength of the Kuroshio Extension jet was estimated using the realistic wind stress curl forcing of 1948 to 2001.

This resemblance in spectrum pattern and the robustness of the preferred forcing period with regard to the detailed parameter values strongly suggest that the Kuroshio Extension jet does not respond passively to the atmospheric forcing over the eastern North Pacific. Rather, through the jet modulation, the differential Rossby wave lag times preferentially amplify the wind stress curl forcing at the decadal timescale. Located where the largest heat loss from the ocean to the atmosphere occurs, the modulated Kuroshio Extension can in turn change the regional SST field and affect the overlying atmospheric jet stream with the same preferential timescale. Indeed, the observed SST anomalies in the Kuroshio Extension region have clear decadal signals (e.g., Fig. 16; see also Schneider and Miller 2001), and recent studies by Qiu (2000) and Vivier et al. (2002) have indicated that these anomalies during the T/P period are in part caused by the low-frequency changes of the Kuroshio Extension jet.

With its long memory, the ocean has been hypothesized by many recent studies to be responsible for setting the timescales of the midlatitude climate variability. Thus far, the proposed ocean processes include 1) limited resonance of the midlatitude baroclinic Rossby waves with basinwide stochastic wind forcing (e.g., Jin 1997), 2) delayed oscillation with the timescale of delay set by the adjustment of the wind-driven gyre or the thermohaline circulation (e.g., Marshall et al. 2001), 3) combination of Rossby wave delay and advection by the mean subtropical/subpolar gyre circulations (e.g., Cessi 2000; Primeau and Cessi 2001), and 4) internal ocean dynamics, such as self-sustained oscillations of western boundary current recirculation gyres (e.g., Dewar 2001). The results presented above suggest that the preferred, decadal modulation of the Kuroshio Extension jet responding to the remote atmospheric forcing in the eastern North Pacific can be another potential

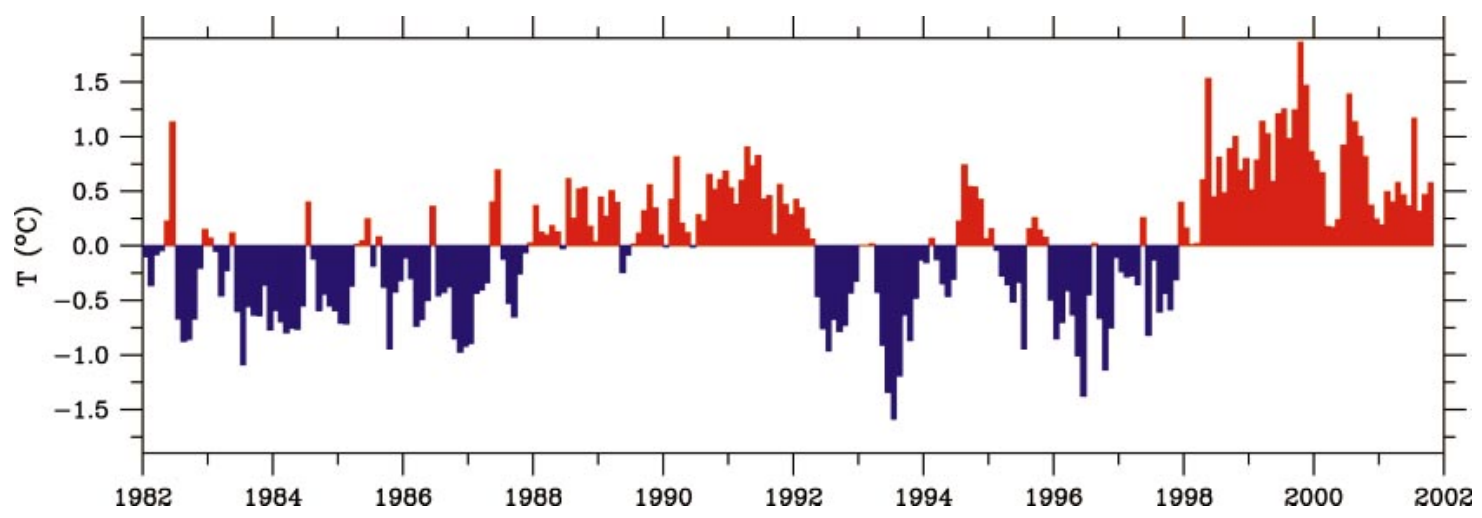

FIG. 16. Monthly SST anomalies averaged in the Kuroshio Extension region of $32^{\circ}-38^{\circ} \mathrm{N}, 141^{\circ} \mathrm{E}-180^{\circ}$. The SST data are compiled by Reynolds and Smith (1994). 
process that contributes to set the timescales of the North Pacific midlatitude climate system. While the baroclinic Rossby waves are an important part of this process, the selected timescale is influenced by the characteristics of the modulated Kuroshio Extension zonal jet: its latitudinal position (which determines $c_{R \mathrm{~A}}$ and $c_{R \mathrm{~B}}$ ), its coherent zonal width $(L)$, and its longitudinal position relative to the dominant surface wind forcing $(C)$.

\section{Conclusions}

Using the available sea surface height data measured by the TOPEX/Poseidon satellite over the past decade, we investigated the large-scale changes in the Kuroshio Extension region of the western North Pacific. The dominant low-frequency signal of the region was characterized by a modulation in the strength of the zonal mean Kuroshio Extension jet: the jet showed a progressively weakening trend from 1993 to 1996 and this trend reversed after 1997. Both the weakening and the restrengthening of the jet are found to appear first in the downstream Kuroshio Extension region in the east and to progress westward at the speed, $\sim 0.04 \mathrm{~m} \mathrm{~s}^{-1}$, of the long baroclinic Rossby waves.

To explore the dynamics underlying the observed modulation of the Kuroshio Extension jet, we examined the baroclinic ocean responses under realistic surface wind forcing. Hindcasting the SSH signals based on linear vorticity dynamics, we found that the weakening trend in the Kuroshio Extension jet in 1993-96 was caused by westward expansions of negative SSH anomalies south of the Kuroshio Extension and positive SSH anomalies north of the Kuroshio Extension. These anomalies had their origins in the eastern North Pacific and were generated by positive and negative wind stress curl anomalies before and after 1992, respectively. In contrast, westward expansions of the positive SSH anomalies to the south of the Kuroshio Extension jet (caused by the negative wind stress curl anomalies after 1997) and the negative SSH anomalies to the north of the Kuroshio Extension jet (caused by the positive wind stress curl anomalies prior to 1997) resulted in a strengthening trend in the zonal mean Kuroshio Extension jet following 1997 . Both of the sign changes in the wind stress curl anomaly field in 1992 and 1997 corresponded to the phase changes of the Pacific decadal oscillations.

The fact that the low-frequency changes in the $\mathrm{Ku}$ roshio Extension jet are forced directly by the interior wind forcing has several implications. First, it indicates that the changes in the zonal mean Kuroshio Extension jet on the decadal timescales can be independent of the upstream Kuroshio variability in the East China Sea and south of Japan. Evidence supporting this notion can be seen in Imawaki et al. (2001), who found no systematic changes in the Kuroshio transport south of Japan during the T/P period. Dynamically, this implies that changes in the wind-driven Sverdrup interior flow, which influ- ences the upstream Kuroshio along the western boundary through mass conservation, are not an important factor for the midlatitude North Pacific ocean-atmosphere coupling. Thermodynamically, this implies that SST anomalies in the Kuroshio Extension region, which the atmospheric circulation is sensitive to on decadal timescales (e.g., Peng et al. 1997; Barnett et al. 1999), are more likely influenced by advection of mean temperature by the anomalous circulation than by advection of temperature anomalies by the mean western boundary current. Evidence supporting this notion can be found in recent upper-ocean heat budget studies for the $\mathrm{Ku}$ roshio Extension region by Qiu (2000), Xie et al. (2001), and Vivier et al. (2002).

By hindcasting the Kuroshio Extension jet strength over the past 45 years using the available NCEP wind stress curl data, we found that the large-amplitude modulation of the Kuroshio Extension jet is not unique to the recent $\mathrm{T} / \mathrm{P}$ decade. Low-frequency changes with a dominant period at $\sim 12$ yr have recurred throughout the past 45 years. To clarify the potential roles of the ocean dynamics in determining this preferred timescale, we examined the baroclinic adjustment processes under stochastic atmospheric forcing. We found that the strength of the Kuroshio Extension jet modulation depends on the frequency, as well as the jet geometry, so that the response to a white-noise, remote wind forcing is amplified at a preferential timescale. With parameter values appropriate for the North Pacific Ocean, the maximum responding amplitude is obtained when the forcing period is $\sim 10 \mathrm{yr}$. At shorter forcing periods, phases of the wind-induced SSH signals across the Kuroshio Extension jet change rapidly along the jet length, decreasing the coherent modulation of the zonal mean $\mathrm{Ku}-$ roshio Extension jet. At longer forcing periods, the small SSH difference across the jet (because of the broad length scales of the wind-induced SSH signals) again suppresses the modulated amplitude of the Kuroshio Extension jet. We suggest that this preferred response by the Kuroshio Extension jet due to the differential Rossby wave delays contributes to an increase in variance and persistence of the coupled climate system of the North Pacific on the decadal timescale.

Acknowledgments. This study benefited from fruitful discussions with Ted Durland, Lee Fu, Fei-Fei Jin, and Niklas Schneider. Detailed comments made by Art Miller and two anonymous reviewers helped to improve an early version of the manuscript. The surface wind stress and heat flux data were provided by the National Centers for Environmental Prediction, and the TOPEX/Poseidon data were provided by the Physical Oceanography DAAC at Jet Propulsion Laboratory. Support from NASA (Contracts 1207881 and 1228847) and NSF (OCE-9911268) is gratefully acknowledged. 


\section{REFERENCES}

Barnett, T. P., D. W. Pierce, R. Saravanan, N. Schneider, D. Dommenget, and M. Latif, 1999: Origins of the midlatitude Pacific decadal variability. Geophys. Res. Lett., 26, 1453-1456.

Cessi, P., 2000: Thermal feedback on wind stress as a contributing cause of climate variability. J. Climate, 13, 232-244.

Chelton, D. B., R. A. DeSzoeke, M. G. Schlax, K. E. Naggar, and N. Siwertz, 1998: Geographical variability of the first baroclinic Rossby radius of deformation. J. Phys. Oceanogr., 28, 433-460.

Deser, C., and M. L. Blackmon, 1995: On the relationship between tropical and North Pacific sea surface variations. J. Climate, 8, $1677-1680$.

— M. M. Alexander, and M. S. Timlin, 1999: Evidence for a winddriven intensification of the Kuroshio Current Extension from the 1970s to the 1980s. J. Climate, 12, 1697-1706.

Dewar, W. K., 2001: On ocean dynamics in midlatitude climate. $J$. Climate, 14, 4380-4397.

Frankignoul, C., and K. Hasselmann, 1977: Stochastic climate models, II, Application to sea-surface temperature variability and thermocline variability. Tellus, 29, 284-305.

— - P. Muller, and E. Zorita, 1997: A simple model of the decadal response of the ocean to stochastic wind stress forcing. J. Phys. Oceanogr., 27, 1533-1546.

Fu, L.-L., and D. B. Chelton, 2001: Large-scale ocean circulation. Satellite Altimetry and Earth Sciences, L.-L. Fu and A. Cazenava, Eds., Academic Press, 133-169.

_- and B. Qiu, 2002: Low-frequency variability of the North Pacific Ocean: The roles of boundary- and wind-driven baroclinic Rossby waves. J. Geophys. Res., 107, 3220, doi:10.1029/ 2001JC001131.

Gill, A., and P. P. Niiler, 1973: The theory of the seasonal variability in the ocean. Deep-Sea Res., 20, 141-177.

Hasselmann, K., 1976: Stochastic climate models, I, Theory. Tellus, 28, 473-485.

Hurlburt, H. E., A. J. Wallcraft, W. J. Schmitz, P. J. Hogan, and E. J. Metzger, 1996: Dynamics of the Kuroshio/Oyashio current system using eddy-resolving models of the North Pacific Ocean. J. Geophys. Res., 101, 941-976.

Imawaki, S., and Coauthors, 2001: Satellite altimeter monitoring the Kuroshio transport south of Japan. Geophys. Res. Lett., 28, 17-20.

Jin, F.-F., 1997: A theory of interdecadal climate variability of the North Pacific ocean-atmosphere system. J. Climate, 10, 1821-1835.

Kalnay, E., and Coauthors, 1996: The NCEP/NCAR 40-Year Reanalysis Project. Bull. Amer. Meteor. Soc., 77, 437-471.

Kawai, H., 1972: Hydrography of the Kuroshio Extension. Kuroshio-Its Physical Aspects, H. Stommel and K. Yoshida, Eds., University of Tokyo Press, 235-354.

Kelly, K. A., 2004: The relationship between oceanic heat transport and surface fluxes in the western North Pacific: 1970-2000. J. Climate, in press.

Latif, M., and T. P. Barnett, 1994: Causes of decadal climate variability over the North Pacific and North America. Science, 266, 634-637.

_ , and - 1996: Decadal climate variability over the North Pacific and North America: Dynamics and predictability. J. Climate, 9, 2407-2423

Mantua, N. J., S. R. Hare, Y. Zhang, J. M. Wallace, and R. C. Francis, 1997: A Pacific interdecadal climate oscillation with impacts on salmon production. Bull. Amer. Meteor. Soc., 78, 1069-1079.

Marshall, J., H. Johnson, and J. Goodman, 2001: A study of the interaction of the North Atlantic Oscillation with ocean circulation. J. Climate, 14, 1399-1421.

Miller, A. J., D. R. Cayan, T. P. Barnett, N. E. Graham, and J. M. Oberhuber, 1994: Interdecadal variability of the Pacific Ocean: Model response to observed heat flux and wind stress anomalies. Climate Dyn., 9, 287-302.

,$- \ldots$, and W. B. White, 1998: A westward-intensified decadal change in the North Pacific thermocline and gyre-scale circulation. J. Climate, 11, 3112-3127.
Mizuno, K., and W. B. White, 1983: Annual and interannual variability in the Kuroshio Current System. J. Phys. Oceanogr., 13, $1847-1867$.

Nakamura, H., G. Lin, and T. Yamagata, 1997: Decadal climate variability in the North Pacific during the recent decades. Bull. Amer. Meteor. Soc., 78, 2215-2225.

Peng, S., W. A. Robinson, and M. P. Hoerling, 1997: The modeled atmospheric response to midlatitude SST anomalies and its dependence on background circulation states. J. Climate, 10, 971987.

Primeau, F., and P. Cessi, 2001: Coupling between wind-driven currents and midlatitude storm tracks. J. Climate, 14, 1243-1261.

Qiu, B., 2000: Interannual variability of the Kuroshio Extension and its impact on the wintertime SST field. J. Phys. Oceanogr., 30, $1486-1502$.

__ 2002: Large-scale variability in the midlatitude subtropical and subpolar North Pacific Ocean: Observations and causes. J. Phys. Oceanogr., 32, 353-375.

— , and K. A. Kelly, 1993: Upper ocean heat balance in the Kuroshio Extension region. J. Phys. Oceanogr., 23, 2027-2041.

-, - and T. M. Joyce, 1991: Mean flow and variability in the Kuroshio Extension from GEOSAT altimetry data. J. Geophys. Res., 96, 18 491-18 507.

Reynolds, R. W., and T. M. Smith, 1994: Improved global sea surface temperature analyses using optimum interpolation. J. Climate, 7, 929-948.

Schneider, N., and A. J. Miller, 2001: Predicting western North Pacific Ocean climate. J. Climate, 14, 3997-4002.

,-- , and D. W. Pierce, 2002: Anatomy of North Pacific decadal variability. J. Climate, 15, 586-605.

Seager, R., Y. Kushnir, N. H. Naik, M. A. Cane, and J. Miller, 2001: Wind-driven shifts in the latitude of the Kuroshio-Oyashio Extension and generation of SST anomalies on decadal timescales. J. Climate, 14, 4249-4265.

Sekine, Y., 1988: Anomalous southward intrusion of the Oyashio east of Japan. 1. Influence of the seasonal and interannual variations in the wind stress over the North Pacific. J. Geophys. Res., 93, 2247-2255.

Stammer, D., 1997: Steric and wind-induced changes in TOPEX/ POSEIDON large-scale sea surface topography observations. $J$. Geophys. Res., 102, 20 987-21 009.

Tai, C.-T., and W. B. White, 1990: Eddy variability in the Kuroshio Extension as revealed by GEOSAT altimetry: Energy propagation away from the jet, Reynolds stress, and seasonal cycle. $J$. Phys. Oceanogr., 20, 1761-1777.

Talley, L. D., 1984: Meridional heat transport in the Pacific Ocean. J. Phys. Oceanogr., 14, 231-241.

Teague, W. J., M. J. Carron, and P. J. Hogan, 1990: A comparison between the Generalized Digital Environmental Model and Levitus climatologies. J. Geophys. Res., 95, 7167-7183.

Tourre, Y. M., Y. Kushnir, and W. B. White, 1999: Evolution of interdecadal variability in sea level pressure, sea surface temperature, and upper ocean temperature over the Pacific Ocean. J. Phys. Oceanogr., 29, 1528-1541.

Trenberth, K. E., and J. W. Hurrell, 1994: Decadal atmosphere-ocean variations in the Pacific. Climate Dyn., 9, 303-319.

Vivier, F, K. A. Kelly, and L. Thompson, 1999: The contributions of wind forcing, waves, and surface heating to sea surface height observations in the Pacific Ocean. J. Geophys. Res., 104, $20767-$ 20788.

— - — , and 2002: Heat budget in the Kuroshio Extension region: 1993-1999. J. Phys. Oceanogr., 32, 3436-3454.

Xie, S. P., T. Kunitani, A. Kubokawa, M. Nonaka, and S. Hosoda, 2001: Interdecadal thermocline variability in the North Pacific for 1958-97: A GCM simulation. J. Phys. Oceanogr., 31, 27982813

Yasuda, T., and K. Hanawa, 1997: Decadal changes in the mode waters in the midlatitude North Pacific. J. Phys. Oceanogr., 27, 858-870.

Zhang, Y., J. M. Wallace, and D. S. Battisti, 1997: ENSO-like interdecadal variability: 1900-93. J. Climate, 10, 1004-1020. 